\title{
محو الأمية المعلوماتية لدى طلاب الملدرسة الثانوية العامة في ضوء متطلبات مجتمع المعرفة
}

$$
\text { إعداد }
$$

أ. د / عماد محمد محمد عطية

أستاذ بقسم أصول التربية

كلية التربية - جامعة أسوان

أ/ سعيلدة حساني محمد سعيد

باحثة ماجستير - بقسم أصول التربية

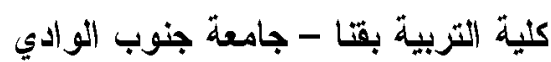

أ. د/ أحمد سيد خليل رحمه الله

أستاذ بقسم أصول التربية

كلية التربية - جامعة أسوان

أ. م. د د/عزة أحمد صادق على

أستاذ أصول التربية المساعد

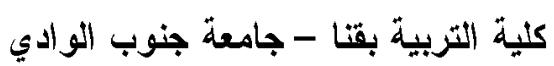


محو الأمية المعلوماتية لدى طلاب المدرسة الثانوية العامة في ضوء متطلبات مجتمع المعرفة

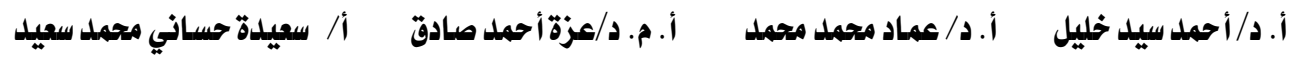

محو الأمية المعلوماتية للى طلاب الملدرسة الثانوية العامة في ضوء متطلبات مجتمع المعرفة

إعداد

أ. د / عماد محمد محمد عطية

أستاذ بقسم أصول التربية

كلية التربية - جامعة أسوان

أ/ سعيلة حساني محمد سعيد

باحثة ماجستير - بقسم أصول التربية

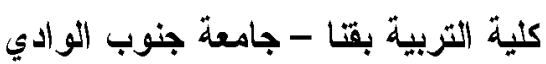

أ. د/ أحمد سيد خليل رحمه الله

أستاذ بقسم أصول التربية

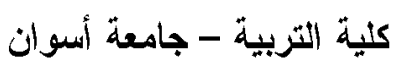

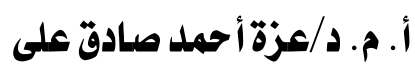

أستاذ أصول التربية المساعد

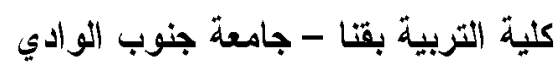

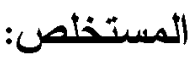

هدفت الدراسة إلى القاء الضوء على محو الأمية المعلوماتية لدى طلاب المدرسة الثانوية

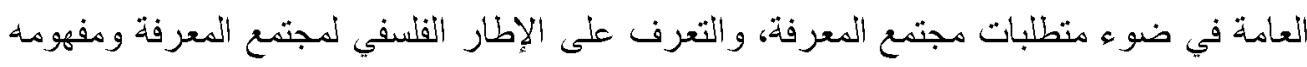

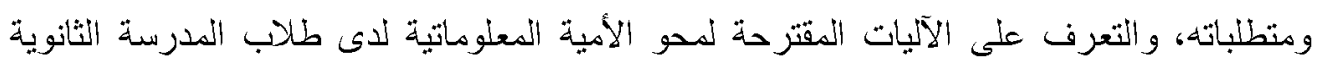

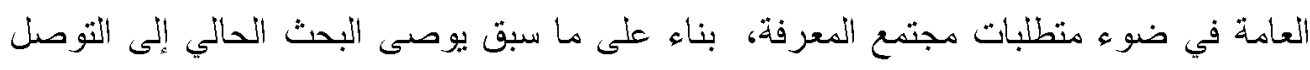

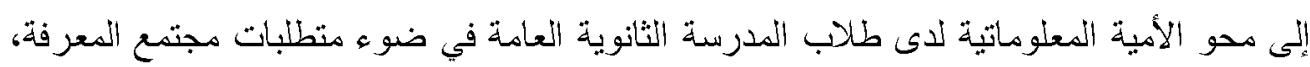

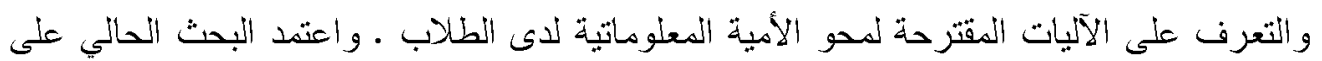

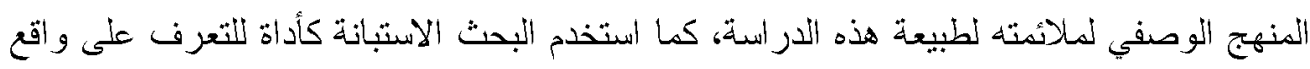

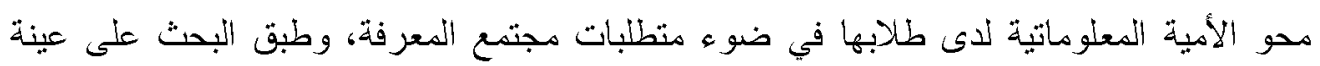

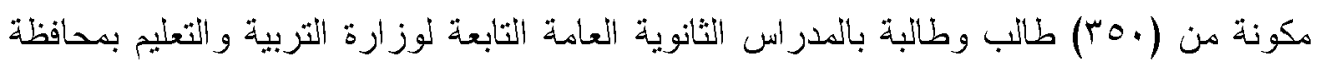

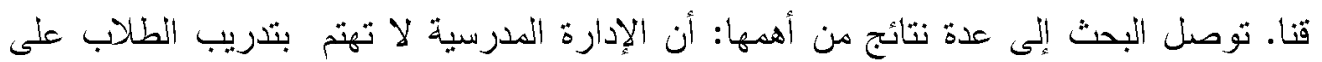

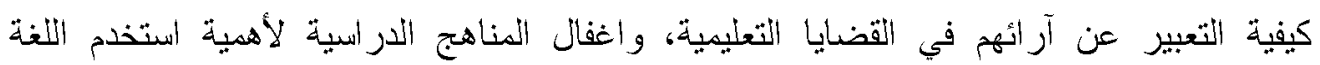

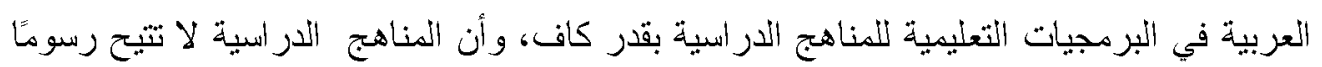

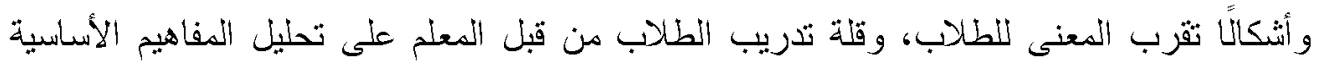

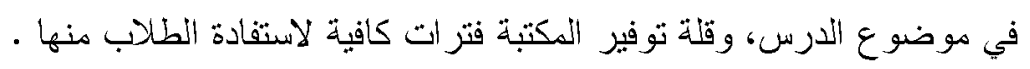
الكلمات الافتتاحية : محو الأمية المعلوماتية ، مجتمع المعرفة . 


\section{محو الأمية المعلوماتية لدى طلاب المدرسة الثانوية العامة في ضوء متطلبات مجتمع المعرفة

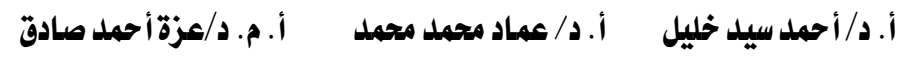 \\ Information literacy among high school students in light of the requirements of the knowledge society}

\section{Prepared by}

\author{
Prof.Dr. Ahmed sayed Khalil \\ Prof.Department of Education Origins \\ Faculty of Education - Aswan University \\ Prof. Dr. Azza Ahmed Sadiq \\ A. Prof. of Education Origins \\ Faculty of Education of Qana \\ South Valley University
}

\author{
Prof. Dr. Emad Mohamed Mohamed \\ Prof.Department of Education Origins \\ Faculty of Education - Aswan University \\ Saida Hassany Mohamed Said \\ M. R. Department Education Origins \\ Faculty of Education of Qana \\ South Valley University
}

\section{Abstract:}

The study aimed to shed light on information literacy among high school students in light of the requirements of the knowledge society, identify the philosophical framework of the knowledge society, its concept and requirements, and identify the proposed mechanisms for information literacy among high school students in light of the requirements of the knowledge society, based on what Previously, the current research aims to reach information literacy among general secondary school students in light of the requirements of the knowledge society, and to identify the proposed mechanisms for its eradication. The current research relied on the descriptive approach for its relevance to the nature of this study. The research also used the questionnaire as a tool to identify the reality of information literacy among its students in light of the requirements of the knowledge society. The research was applied to a sample of (350) male and female students in public secondary schools of the Ministry of Education in Qena Governorate. . The research reached several results, the most important of which are: that the school administration does not care about training students on how to express their opinions on educational issues, and the curricula neglect the importance of using the Arabic language in educational software for the curricula to a sufficient extent, and that the curricula do not provide fees and forms that approximate meaning to students, And the lack of training of students by the teacher to analyze the basic concepts in the subject of the lesson, and the lack of the library providing sufficient periods for students to benefit from them.

Keywords: information literacy, the knowledge society. 
شهد العالم في السنوات الأخير من القزن الحادي و العشرين تطورًا كبيرًا في التكنولوجيا

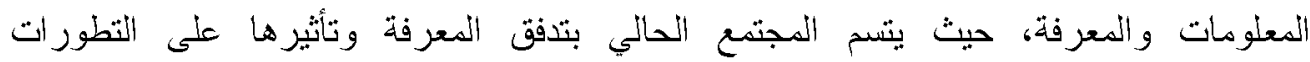

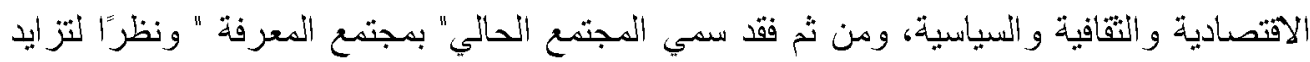

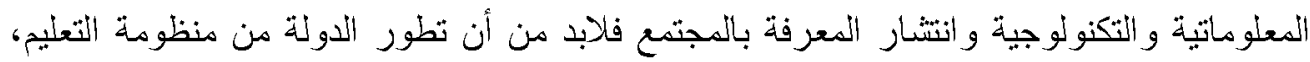
لأن التعليم المصدر الأساسي في تقدم الدول وخاصدة مصر .

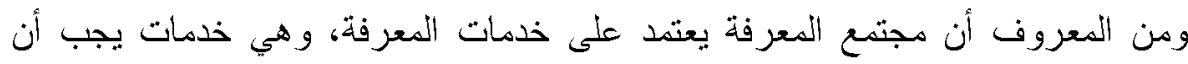

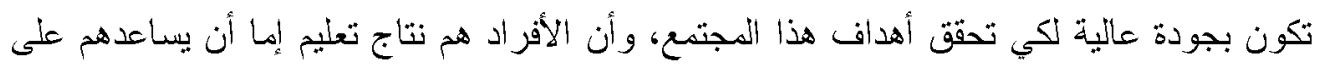

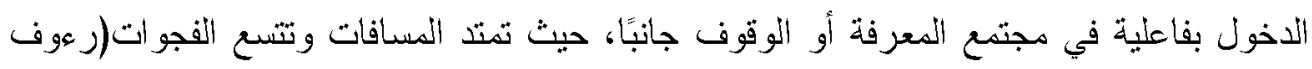

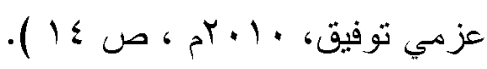

ويعد مجتمع المعرفة هو ذلك المجتمع الذبي يقرر بناء سياساته واستر اتيجياته المستقبلية

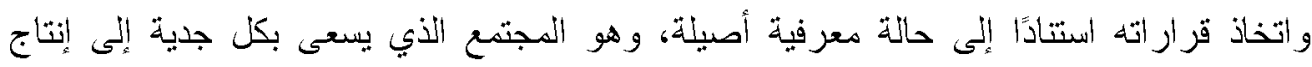

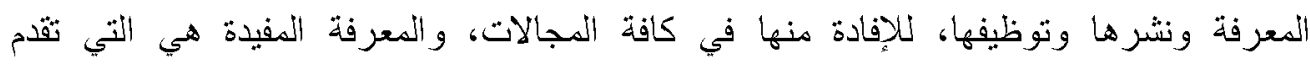

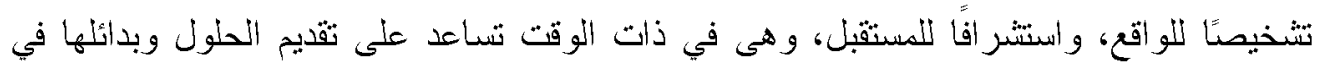

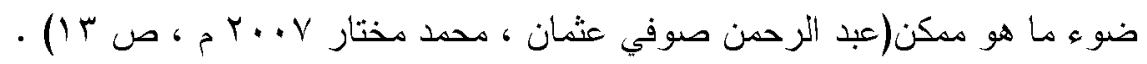

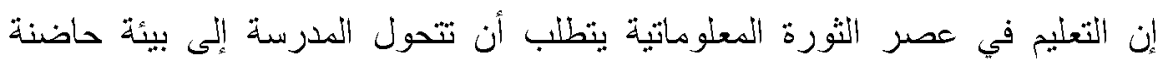

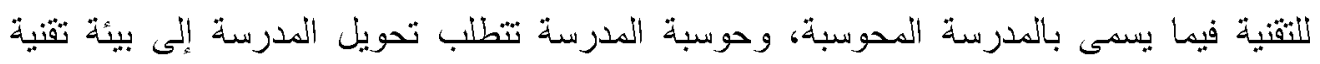

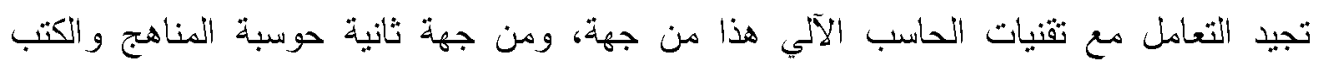

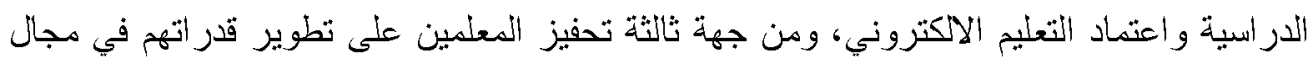

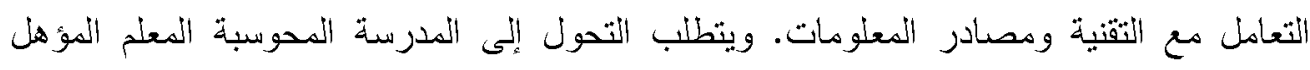

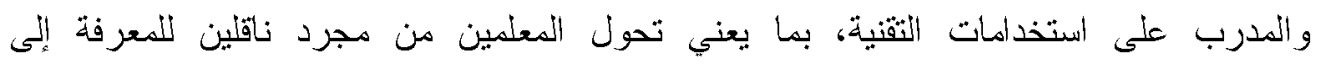

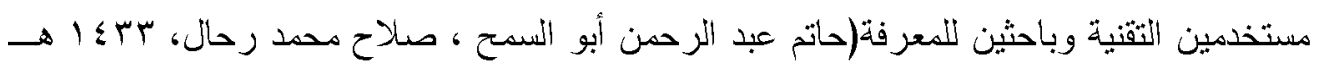

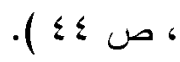

ومن المؤكد أن اعتماد المجتمع المصري على إنتاج المعلومات يضع اللبنة الأساسية

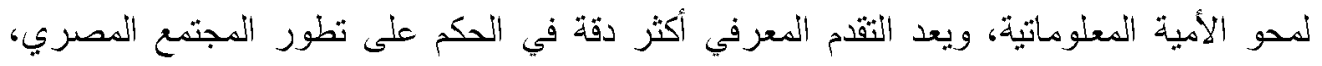

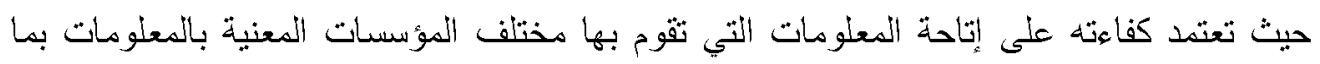

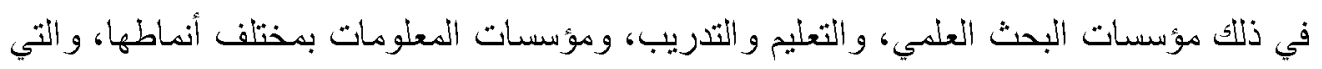




\section{محو الأمية المعلوماتية لدى طلاب الملدرسة الثانوية العامة في ضوء متطلبات مجتمع المعرفة}

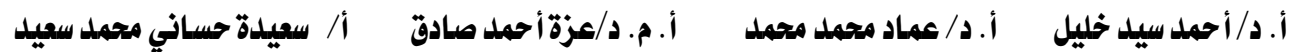

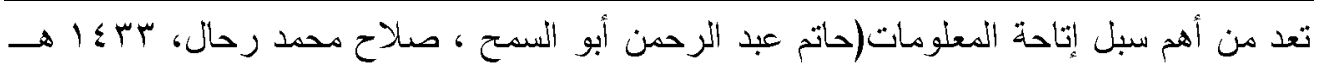

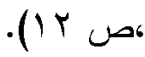

كما حظيت المدرسة الثانوية العامة باهتمام كبير في هذا المجال حيث عكفت عدة دول

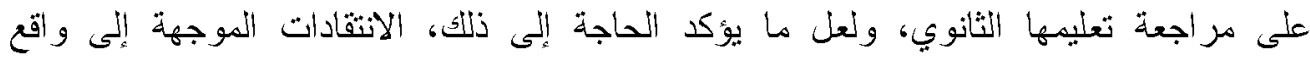

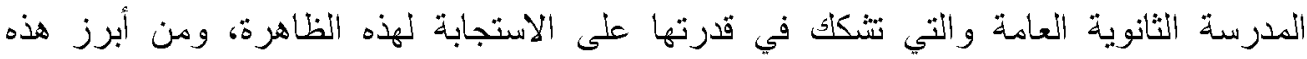

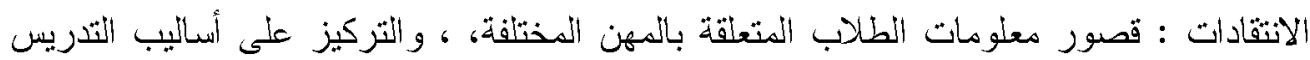

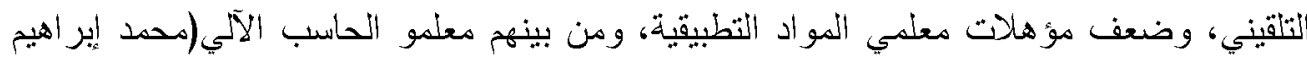

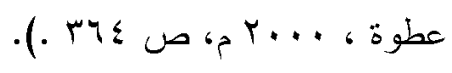

لذلك ظهرت في اللسنوات الأخيرة مفاهيم جديدة لمجتمعاتتا كالمعلوماتية، والتعلم

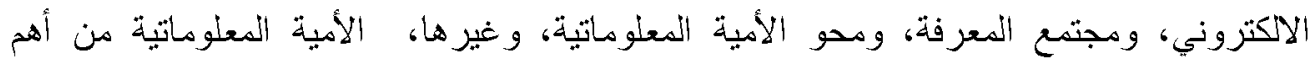

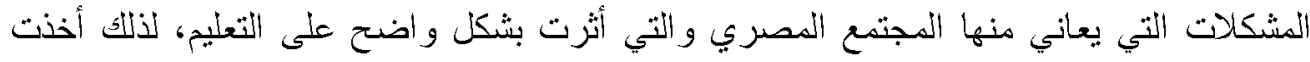

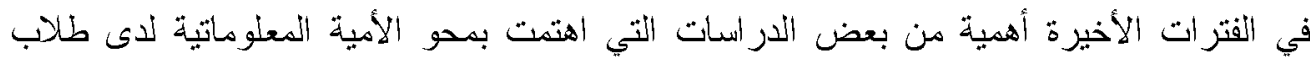

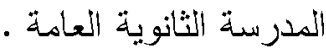

مشكثة البحث

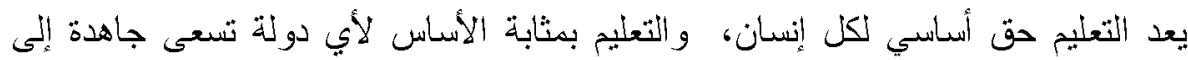
التتمية و التققم، فالتعليم ليس له سن أو وقت معين، فلابد من وجود الحواسيب بالمكتبة واتصالها بالإنترنت فهو شيء حتمي وهو بنك المعرفة و المعلومات بالنسبة للطالب. وقد أسهوت تكنولوجيا الاتصال في انتتار وسرعة التدفقات المعرفية في مجال الأفكار

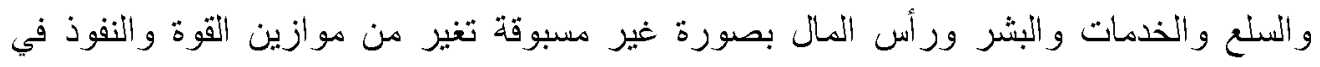

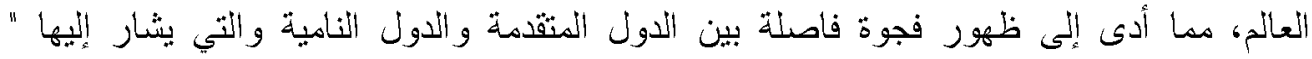

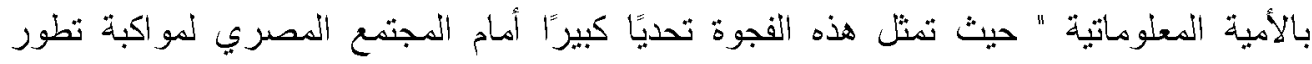

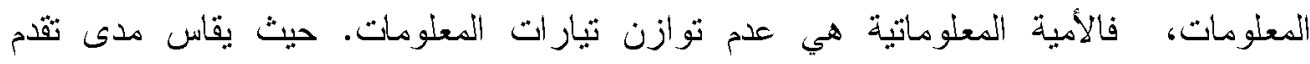

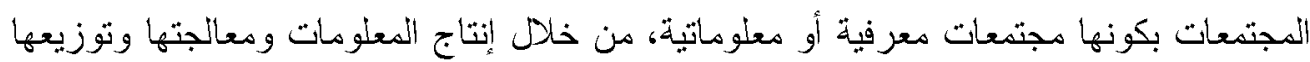

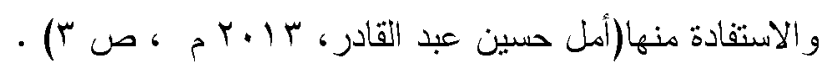

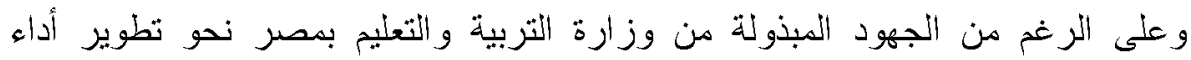

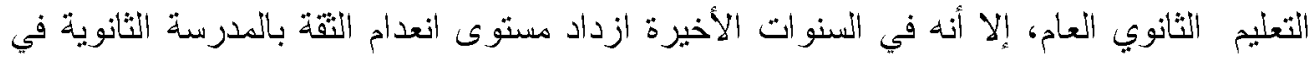

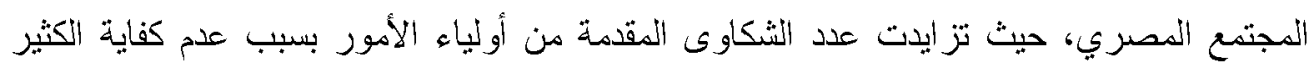

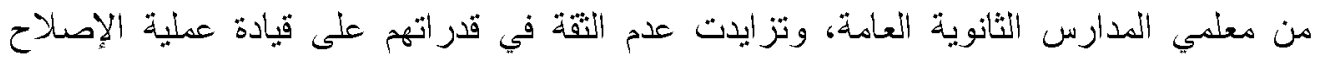




\section{محو الأمية المعلوماتية لدى طلاب الملدرسة الثانوية العامة في ضوء متطلبات مجتمع المعرفة}

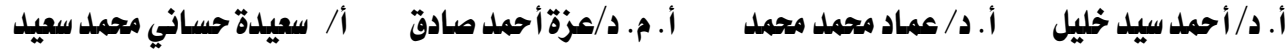

و التعليم لطلابهم، ولعل هذا ما أكدته عديد من ورش العمل و المؤتمرات وحلقات النقاش التي عقدت

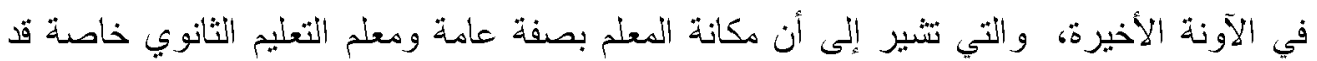

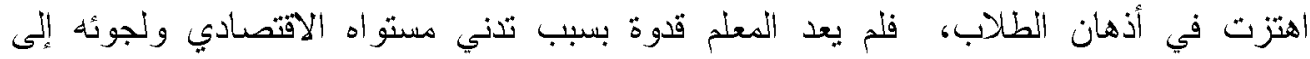

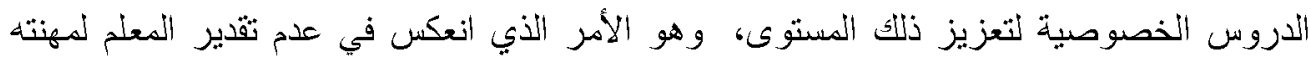

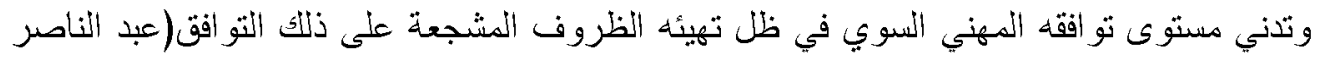

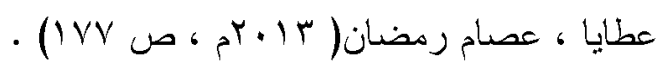

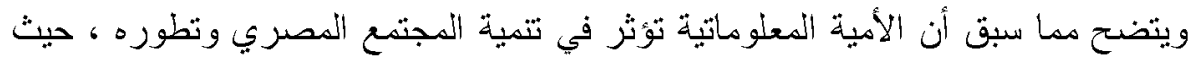

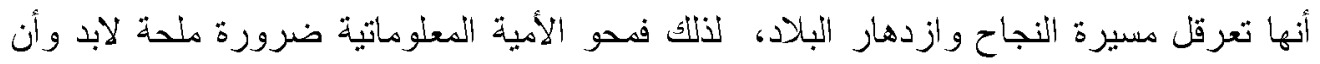

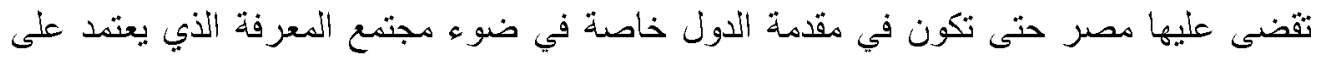

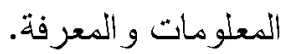

ويمكن تحديد مشكلة الدر اسة الحالية في التساؤلات الآثية :

\section{تساؤلات البحث :}

1- ما الإطار الفكرب و الفلنفي لمجتمع المعرفة وما متطلباته ؟

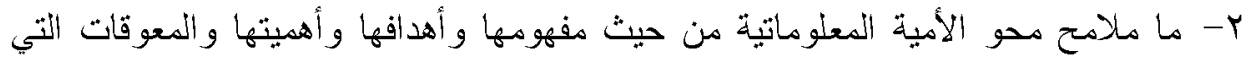

$$
\text { تواجهـا مأب }
$$

ب- ما الآليات المقترحة لمحو الأمية المعلوماتية لدى طلاب المدرسة الثانوية العامة في

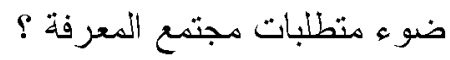
أهداف البحث : أبرء

1- التعرف على الإطار الفكري و الفلسفي لمجتمع المعرفة من حيث مفهومه ومتطلباته.

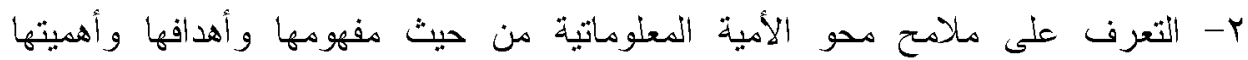
و المعوقات التي تو اجهمها. ب- التعرف على الآليات المقترحة لدحو الأمية المعلوماتية لدى طلاب المدرسة الثانوية العامة في ضوء متطلبات مجتمع المعرفة. أهمبة البحث : تتبع أهمية الدر اسة الحالية من عدة اعتبار ات هي :

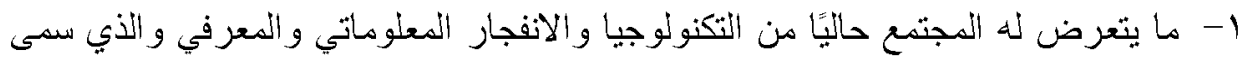

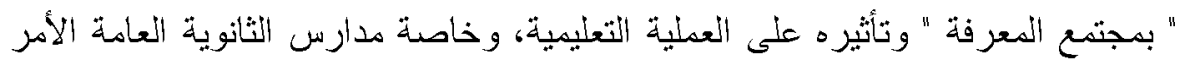

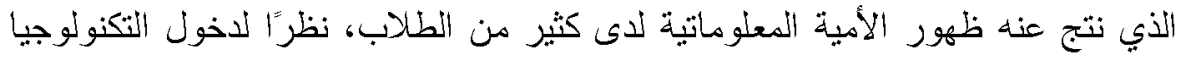




\section{محو الأمية المعلوماتية لدى طلاب المدرسة الثانوية العامة في ضوء متطلبات مجتمع المعرفة}

\section{أ. د/أحمد سيلد خليل أ. د/ عماد محمد محمد أ. م. د/عزة أحمد صادق أ/ سعيدة حساني محمد سعيد}

بحياتهم فجأة لذلك يتطلب إجراء دراسات مستمرة لمعرفة الإطار الفكري والفلسفي

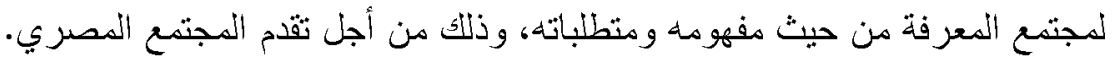

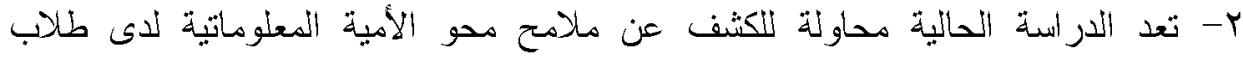

المدرسة الثانوية العامة في ضوء متطلبات مجتمع المعرفة . r- تعد الدر اسدة الحالية محاولة للتعرف على الآليات المقترحة لمحو الأمية المعلوماتية لدى لئى طلاب المدرسة الثانوية العامة في ضو هـ منطبات مجتمع المعرفة. مصطلحات البحث : البح

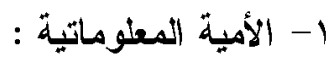

تعرف الأمية المعلوماتية على أنها : "عدم القدرة على تحديد وإدراتك مدى الحاجة إلىى

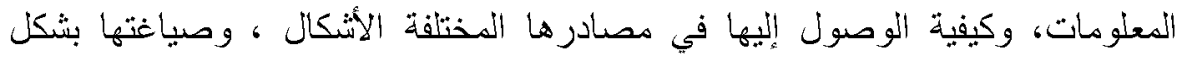

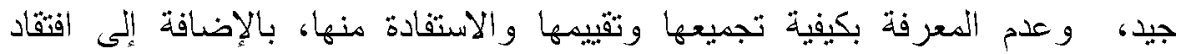

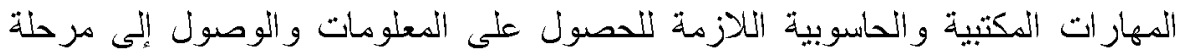

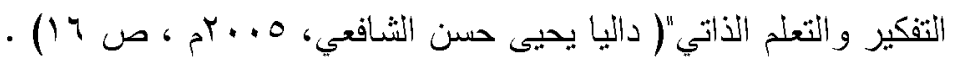

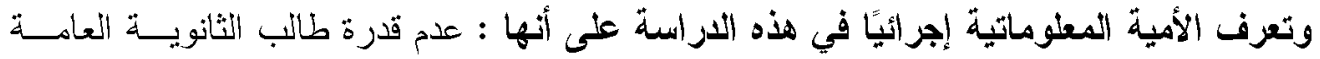

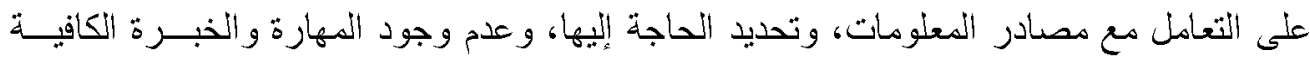
اللتعامل معها و الوصول إلى تحقيق الاحتياجات لبناء مجتمع المعرفة. r- بحو الأمية المطوماتية :

" هي المعرفة التي تسمح للفرد بان بقوم بعمله بكفاءة وفاعلية في مختلف الظروف التي يوجد فيها، وبالتالي سيختلف مدلول المصطلح من شخص لآخر تبعا لتناك الظروف (أمل فئل

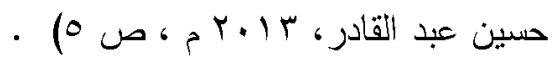

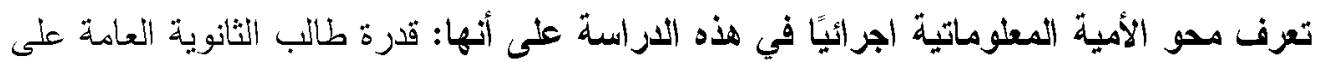

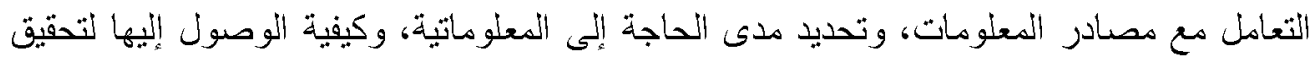

متطلبات مجتمع المعرفة.

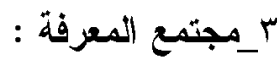

يعرف على" أنه ذلك المجتمع الذي يقوم أسساسًا على نشر المعرفة وإنتاجها وتوظيفها

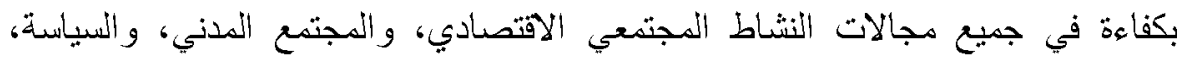

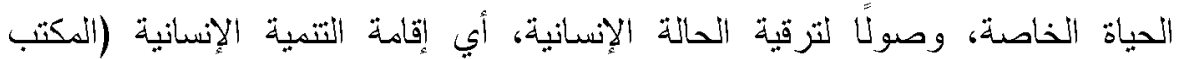

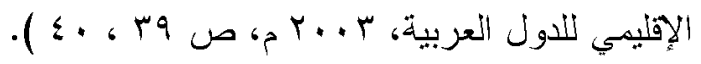




\section{محو الأمية المملوماتية لدى طلاب الملدرسة الثانوية العامة في ضوء متطلبات مجتمع المعرفة}

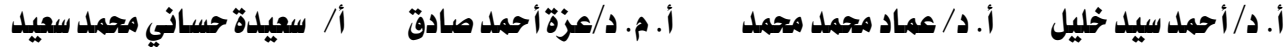

يعرف مجتمع المعرفة إجرائيًا في هذه الدراسة على أنه : المجتمع الذى تتنج فيه المعلومات بشكل

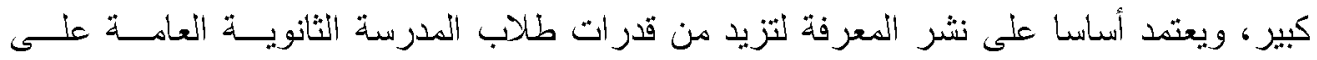
استخدام مصادر المعلوماتية، وكذلك تزيد من كفاءتهم ومهارتهم في استخدامها . منهج البحث :

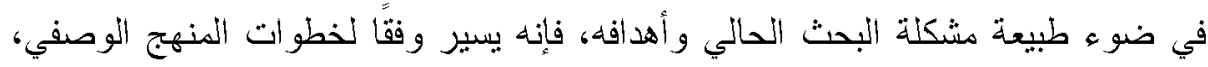

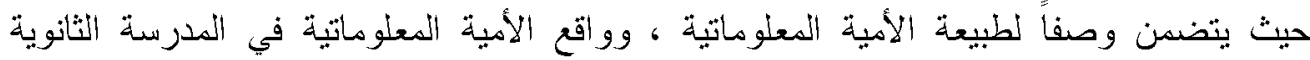

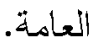

بناء على ما سبق يسير الجزء التاني من البحث ثلاث محاور ، حيث يدور المحور الأول حول مفهوم الأمية المعلوماتية وأسبابها ، أما المحور الثناني يدور حول محو الأمية المعلوماتية

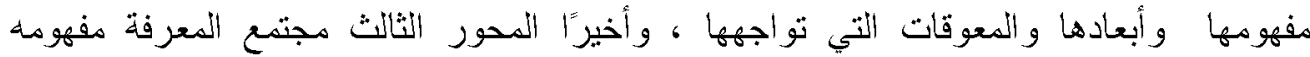
ومتطلباته ، وفيما يلى عرض تفصيلي لتنلك الأقسام على النحو الآتي:

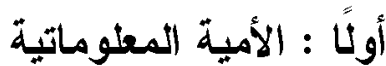
_ _ مفهوم الأمية المطوماتية تم ترجمة مصطلح Information Illiteracy بمفردات كثيرة منها مستوى التعليم، و التثافة المعلوماتية ، ومحو الأمية المعلوماتية، الوعي المعلوماتي وغيرها، وقد اهتم بهذا المفهوم كثير من المنظمات المتخصصة والباحثين ، ففي ظل هذه الثورة المعلوماتية ، ظهرت الأمية

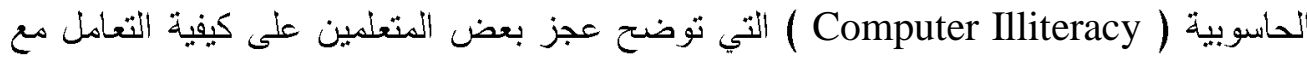
الحاسب الآلي، كما أن هناك الأمية المعلوماتية ( Illiteracy Information) التي تؤكد على التى عجز كثير من المتعلمين على الوصول إلى معلوماتهم وتحديد الحاجة إلى المعلومات وكيفية

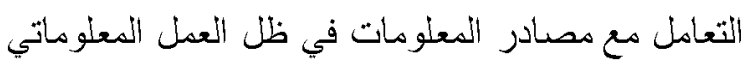
المعقد (Eisenberg, 2008. 39-47). ويمكن النظر إلى الأمية المعلوماتية على أنها أحد عناصر الأمية الثثافية بوجه عام،

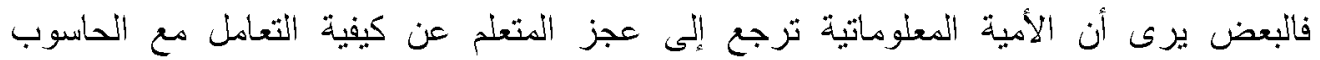
والتقنيات الحديثة، والبعض يربطها بعدم قدرة الأفر اد على اكتساب المهار اتل الأساسية وكيفية

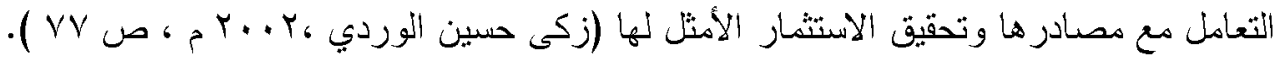
ب_ أسباب ظهور الأمية المعلوماتية نتيجة للتطور الهائل في التكنولوجيا و التي مرت بها الهجتمعات فقد قسمت المجتمعات إلى الى ثلاث فئات منها مجتمعات مشاركة وهي التي يمكنها أن تقوم بإنتاج التكنولوجيا في مجال 


\section{محو الأمية المملوماتية لدى طلاب الملدرسة الثانوية العامة في ضوء متطلبات مجتمع المعرفة}

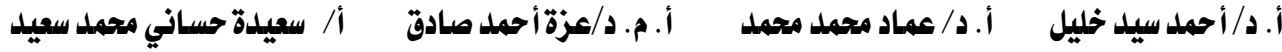

المعلومات و الاتصالات، و هناتك مجتمعات متصلة وهي التي يمكنها التو اصل مع العالم من خلال

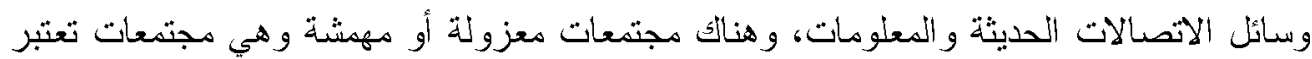

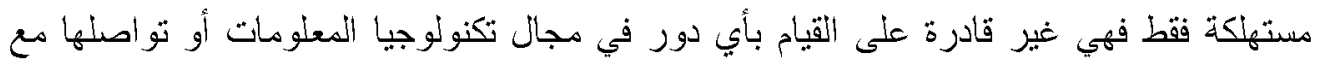

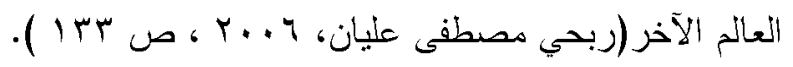

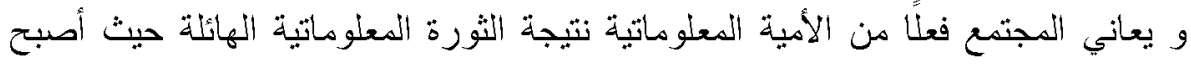

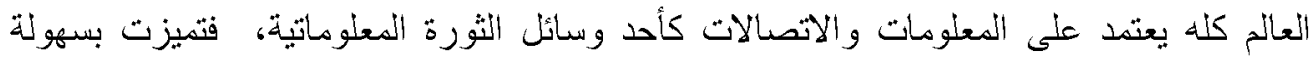
ومرونة وبساطة في الاستعمال فهي توصل المعلومة للفرد في أبي مكان كان وتجعل العالم كله قرية صغيرة، لذلك فهي ساهمت في حل كثير من المشكلات التي بعاني منها الإنسان وأيضًا

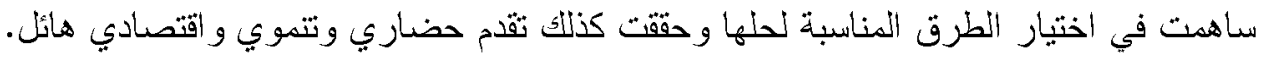

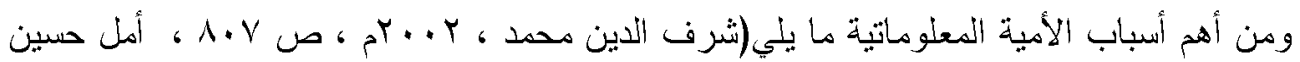

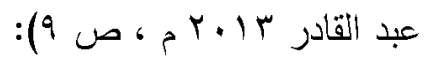

1- نظام التعليم المتبع يعانى من الجمود ويعتمد على التلقين والحفظ. قلة الاهتمام بالمورد البشربي المؤهل للتعليم وتدريبه على التكنولو جيا الحديثة. ץ- الاكتفاء بالكتب الدراسية و الانثغال بمصادر الحصول علئل على المعلومات المختلفة ( كثبكة الانترنت

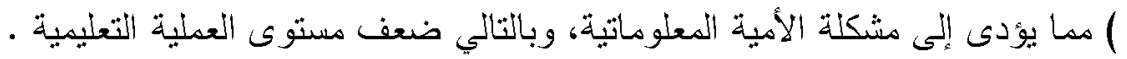

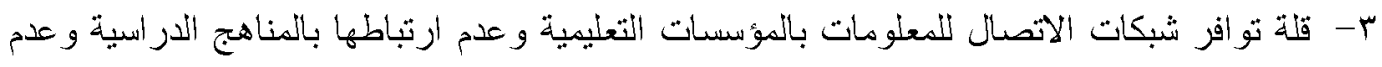
التعرف على أساليب التكنولوجيا الحديثة ومعرفة الوصول لمصادر المعلومات في مختلف أثكالها. ثانيًا : محو الأمية المعلوماتية أـ نشأدة وتظور مفهوم محو الأمية المطظوماتية حركة محو الأمية المعلوماتية نتجت من حركة الصدية الصعاح التعليم التي اجتاحت أمريكا في

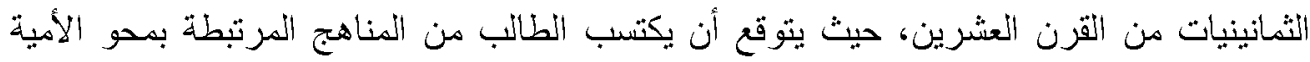

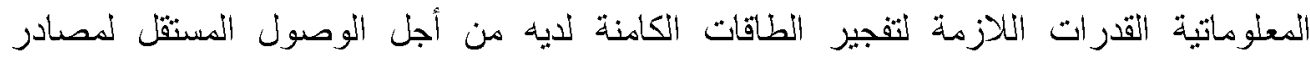

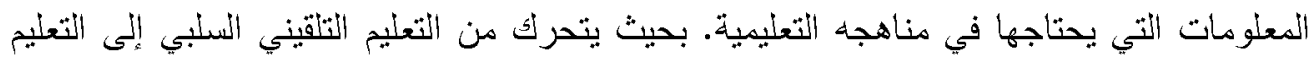

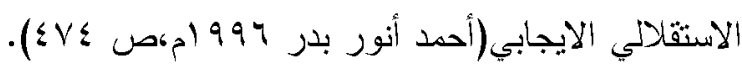

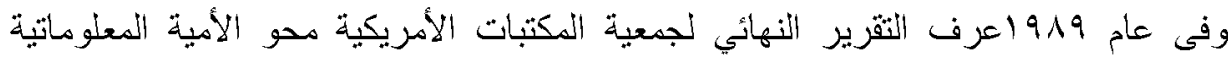

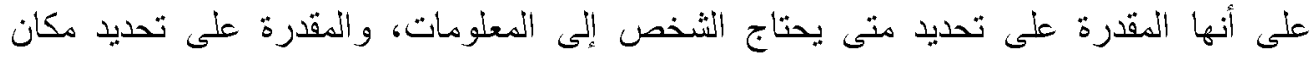

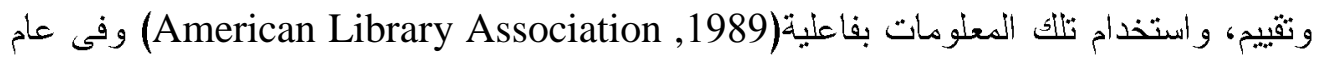

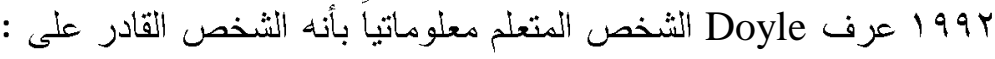




\section{محو الأمية المعلوماتية لدى طلاب الملدرسة الثانوية العامة في ضوء متطلبات مجتمع المعرفة}

\section{أ. د/أحمد سيلد خليل أ. د/ عماد محمد محمد أ. م. د/عزة أحمد صادق أ/ سعيدة حساني محمد سعيد}

1- معرفة تحديد المعلومات الصحيحة التي تجعله قادرًا على اتخاذ القرار ات الذكية. r- كيفية تحديد حاجته من المعلومات.

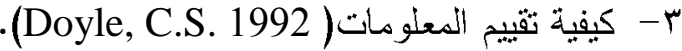

ب_ أهداف محو الأمية المعلوماتية في المدرسة الثانوية العامة

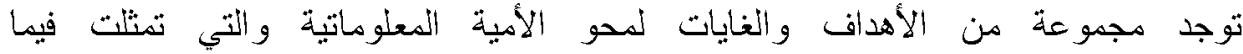
يلي) (Lannuzzi, Patricia, 1999): الهدف الأول : معرفة توضيح الحاجة للمعلومات : 1. مباغة أسئلة عن الحاجة للمعلومات. r. تفسير المفاهيم والمصطلحات الرئيسية للمعلومات. الهدف الثاني : إعداد وتخزين وتتظيم المعلومات :

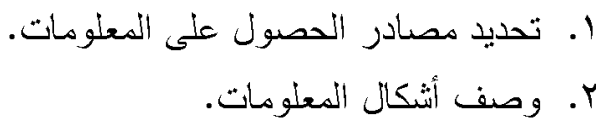
الهدف الثالث : اختبار طرق البحث وأنظمة استرجاع المعلومات : ا. ا. وصف نوع المعلومات التي نحتاجها في شرح البيانات. r. أبتيار أدوات البحث المناسبة. جـ_أهية محو الأمبية المعلوماتية

تتحدد أهمية محو الأمية المعلومانية في الداجة إلى إكساب الفرد مجموعة من

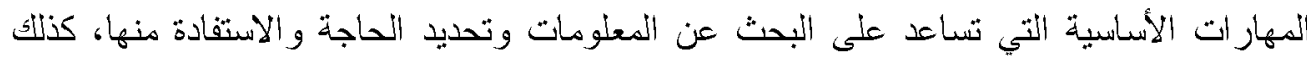
العمل على محو الأمية المعلوماتية تعتبر وسيلة لقوة الفرد تمكنه من استثار المعلومات وتساعده على الوصول إلى الحقبقة كما أنها تكسبد القدرة على الحوار و المناقثتة وتزوده بخبرات في البحث

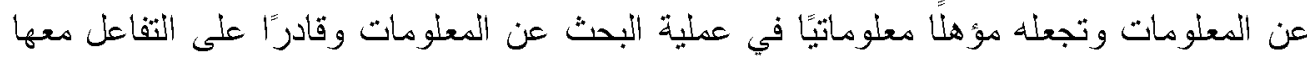

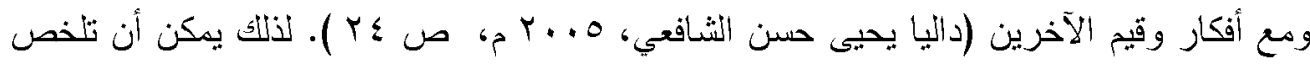

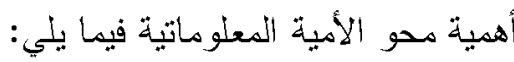

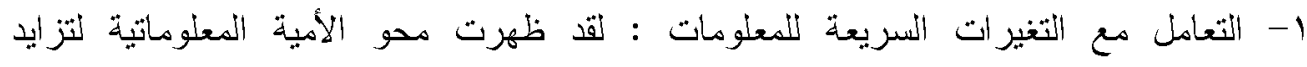
المعلوماتية نظرًا لوجود الكتب و المجلات والإنترنت ووسائل الإعلام الأمر الأى جعل الإنل

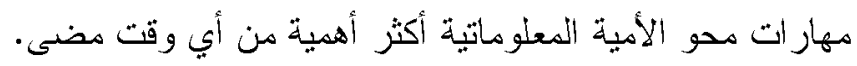

r- الاستخدام الأخلاقي للمعلومات : إن المعلومات يمكن أن تستخدم بشكل سلبى كمن يستخدم

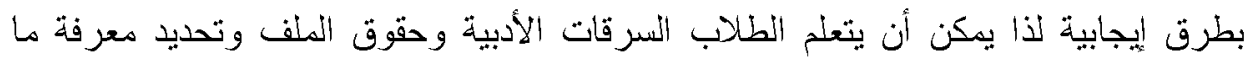




\section{محو الأمية المعلوماتية لدى طلاب الملدرسة الثانوية العامة في ضوء متطلبات مجتمع المعرفة}

\section{أ. د/أحمد سيلد خليل أ. د/ عماد محمد محمد أ. م. د/عزة أحمد صادق أ/ سعيدة حساني محمد سعيد}

يهمه فالمعايير الأخلاقية وقضايا الملكية القانونية عرفت من قبل منظمات متخصصدة (وفاء

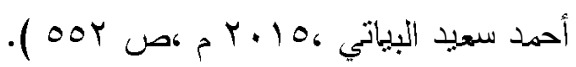
r- النعلم مدى الحياة : محو الأمية المعلوماتية له علاقة وثيقة بالتعلم مدى الحياة لإجر اء العديد من المهاز ات و اتخاذ القز ارات.

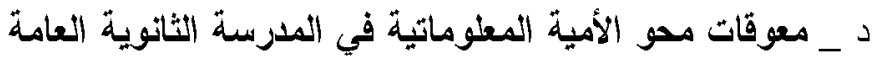

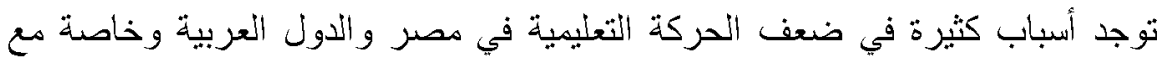
ظهور الثورة المعلوماتية التي دخلت على المجتمعات العربية فأحدثت فيها تغير ات سريعة في

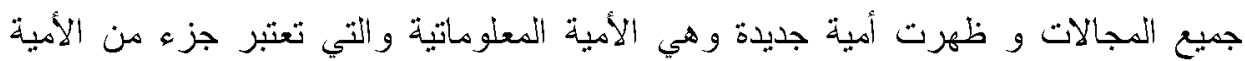

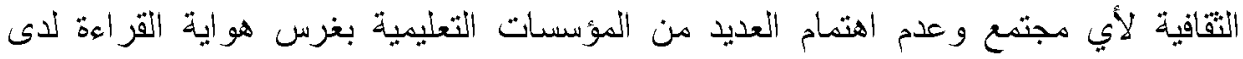

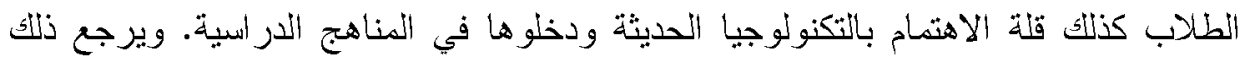
إلى مجمو عة من المعوقات التي يمكن تصنيفها إلى :

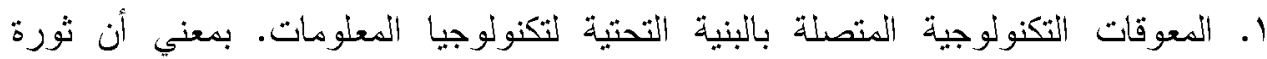

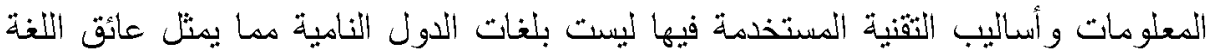

$$
\text { للوصول إلى المعلومات من قبل الباحثين. }
$$

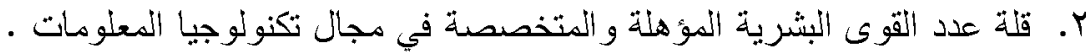
r. المعوقات المعنوية المتصلة بالمكانة والسمعة العلمية في سوق النشر خاصة في موضوع

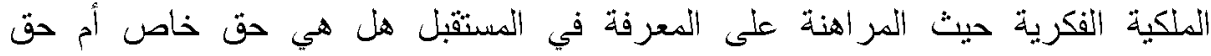

$$
\text { جماعي. }
$$

؛. المعوقات القانونية المتصلة بالملكية الفكرية وحقوق المؤلفين •

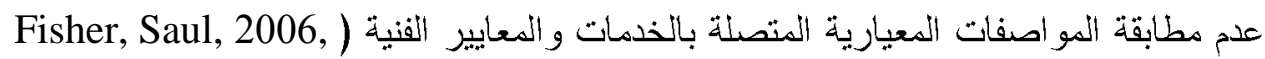
(127-145

ثالثًا : مجتمع المعرفة

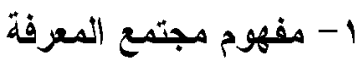

يعيش العالم مرحلة جديدة من التطور التكنولوجي اختلطت فيها نتائج الثورات منها الثثورة

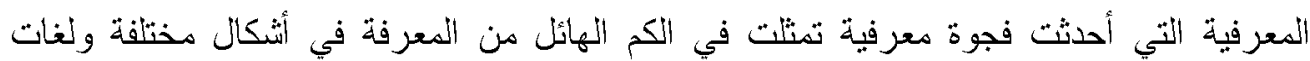

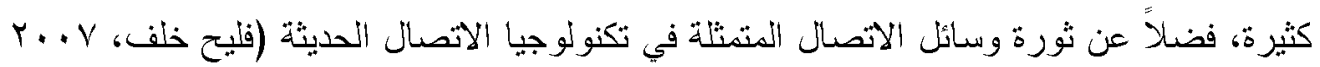

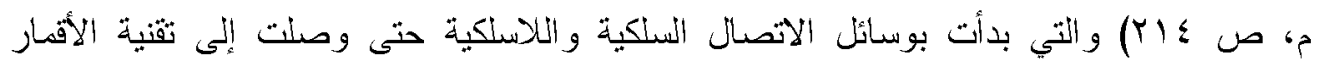
الصناعية، وأخيرًا ثورة الحاسبات الاكترونية التي دخت في كل المجالات واندمجت بوسن وساثل 


\section{محو الأمية المعلوماتية لدى طلاب الملدرسة الثانوية العامة في ضوء متطلبات مجتمع المعرفة}

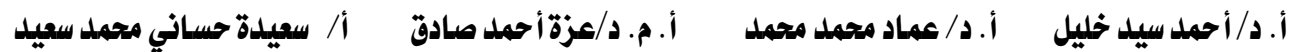

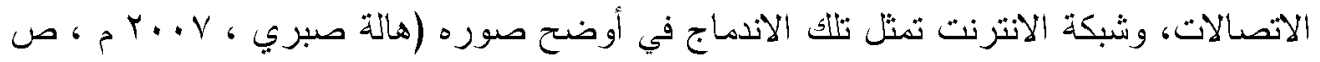

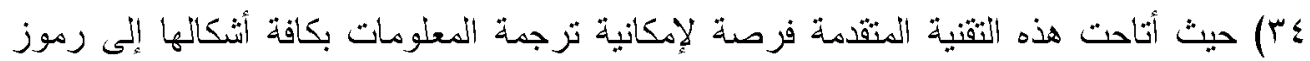

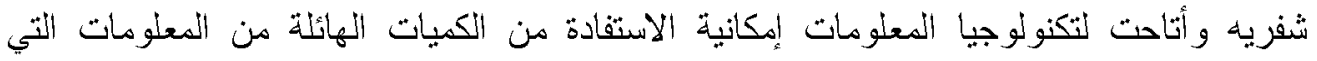

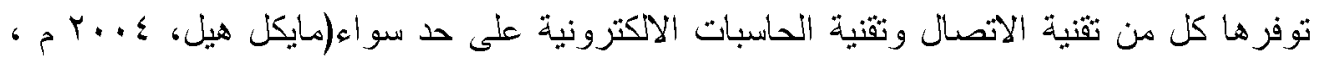
ص ص (1) م (1).

وقد تعددت التعريفات حول " مجتمع المعرفة " فهناك عديد من التقارير و الأدبيات التي

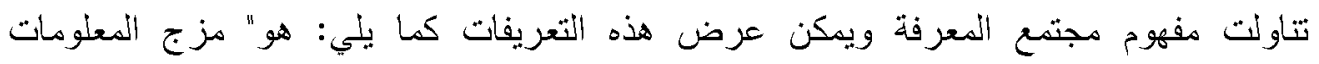

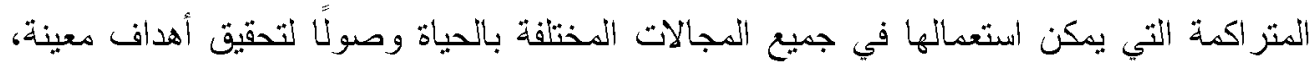

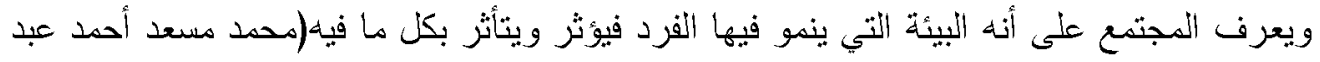

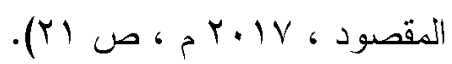

كما يعرف مجتمع المعرفة على أنه " المجتمع الذي بعتمد بشكل كلي على المعلومات

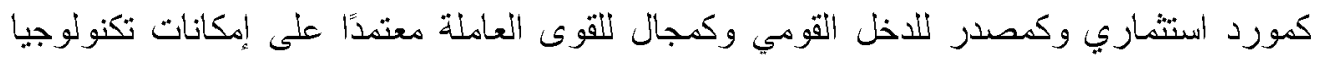

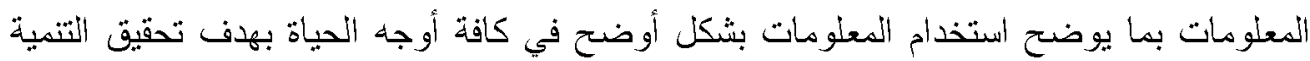

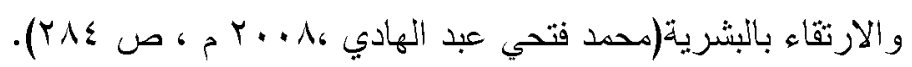

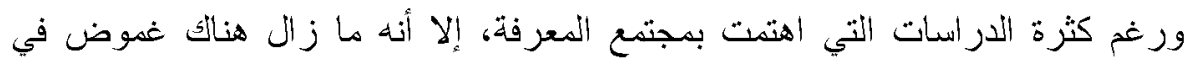

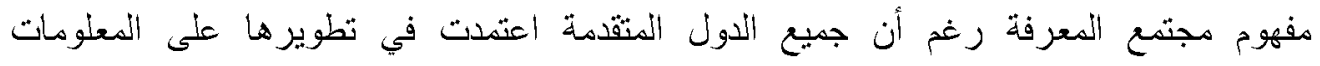

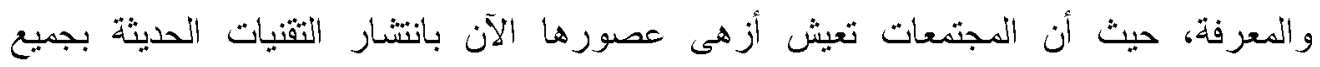

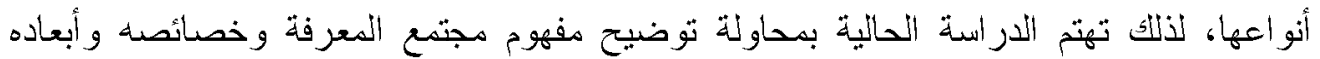
ومتطلباته التربوية و التي تؤثر بشكل واضح في التعليم بصفة عامة و المدرسة الثانوية العامة بصفة ونهة

خاصة.

وترى الدراسة الحالية أن مجتمع المعرفة هو "ذللك المجتمع الذبي يهدف إلى نثر المعرفة بين

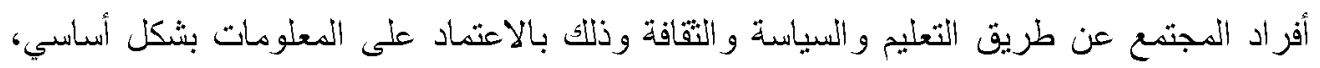

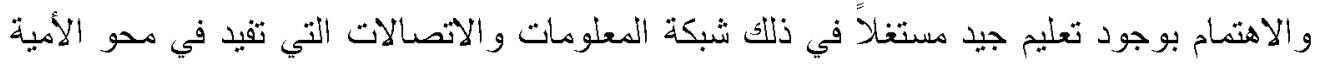

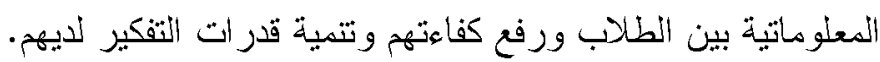

\section{r T بائص مجتمع المعرفة}

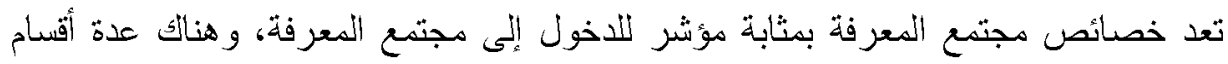

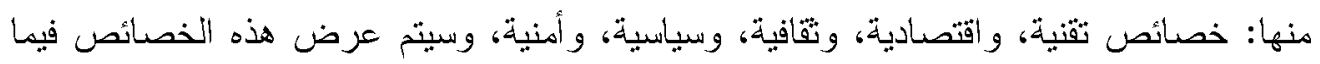
يلي: 


\section{محو الأمية المعلوماتية لدى طلاب الملدرسة الثانوية العامة في ضوء متطلبات مجتمع المعرفة}

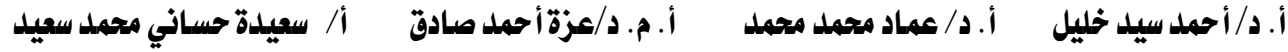

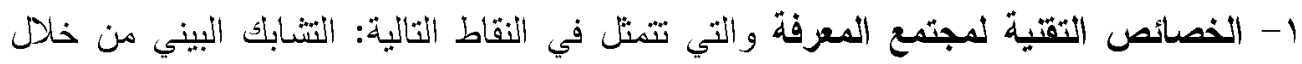
التطور الملحوظ لوسائل الاتصـالات الجديدة ، النمو النريع في النثر الالكتروني ، تطوير

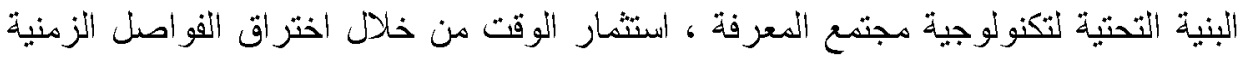

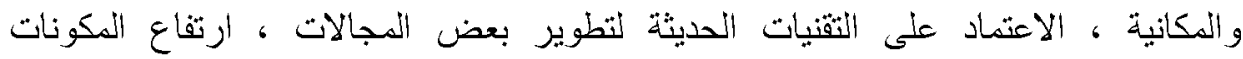

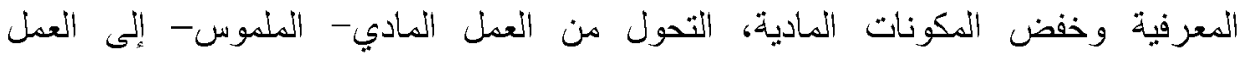
الافتراضي ، وضع التكنولوجيا موضع الإنسان في كثير من الأعمال (الأتدتة). (هبة إبر اهيم الهيم

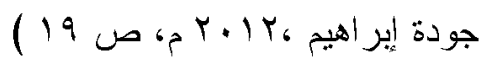

\section{r- الخصائص الاجتماعية لمجتمع المعرفة}

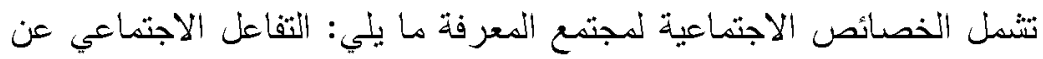

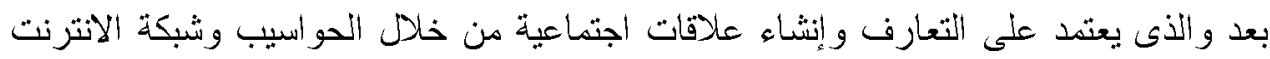
وظهر ذلك من خلال المحادثات بين أفراد المجتمعات المختلفة فصارت كل المجتمعات كثرية

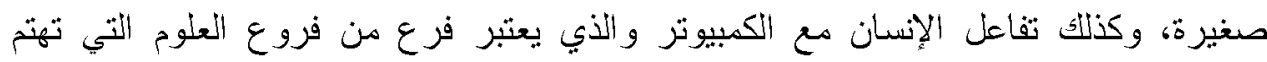

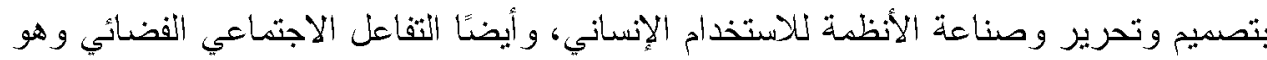

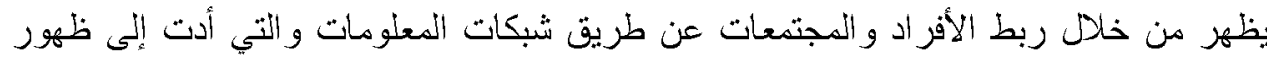

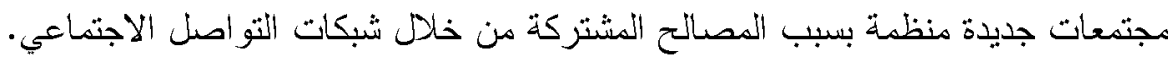

\section{ب-الخصائص الثقافية لمجتمع المعرفة}

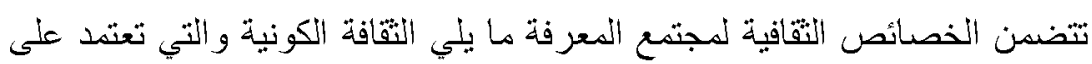

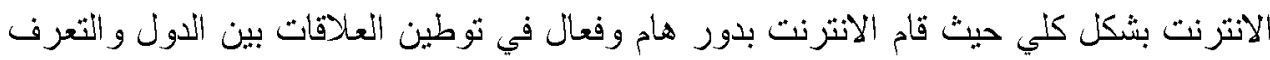

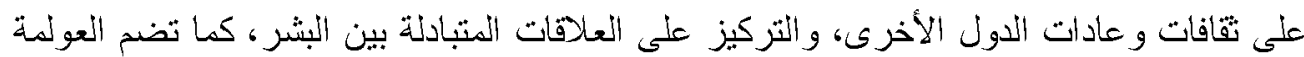

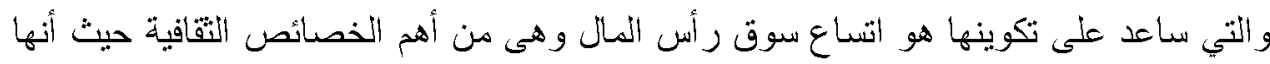
ساهمت في أن يكون العالم كله قرية صغيرة.

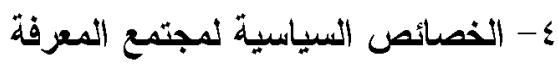
أ- - تتمثل الخصائص السياسية لمجتمع المعرفة في النقاط التالية: اللاحدود: ويقصد بها تغاضى

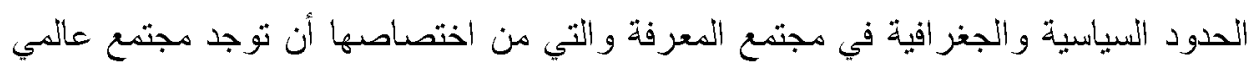

$$
\text { لا بعترف بالحدود السياسية بين الدول. }
$$

ب- الحكومة الاككترونية: لضرورة ما يتطلبه مجتمع المعرفة من تغيرات في المجالات المختلفة

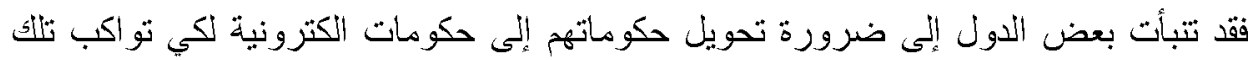




\section{محو الأمية المملوماتية لدى طلاب الملدرسة الثانوية العامة في ضوء متطلبات مجتمع المعرفة}

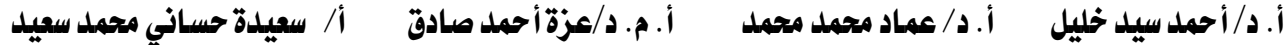

التطور ات، لذا قامت كثير من حكومات الدول المتقدمة في العالم ببذاء قو اعد معلوماتية وطنية خاصدة بها وكذلك تحولت بعض الدول إلىى الحكومة الالكترونية و التي تقوم على مبادئ أساسية منها: بناء الخدمة العامة التي تدور حول احتياجات المواطنين، وجعل الحكومة وخدماتها

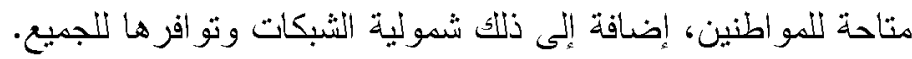
ج- حرية التعبير عن الر أبي: افترن التقدم العلمي والرقفي بإطلاق حرية التعبير عن الترأبي، ويتم

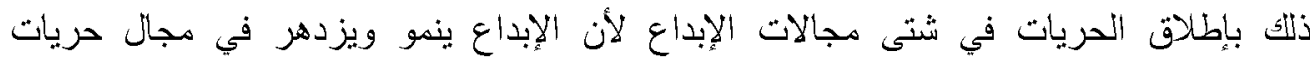

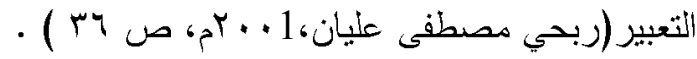

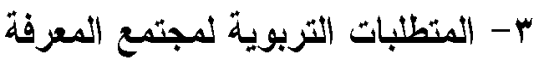
بعتبر مجتمع المعرفة ثورة تزبوية لذا أصبحت التربية هي المشكلة و الحل فقد أثثار تثرير

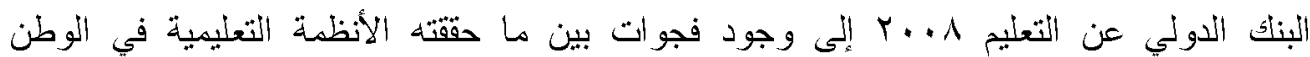

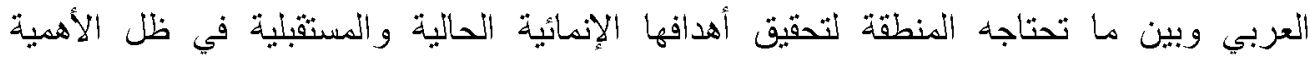

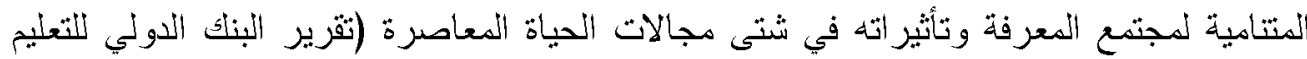

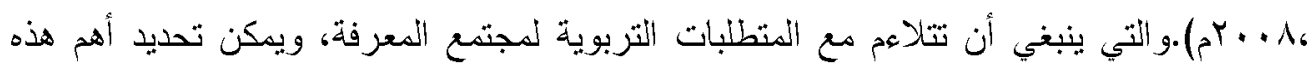
المتطلبات فيما يلي:

( ) التحول إلى المجتمع الالكتروني من خلال دمج التقنية المعلوماتية في التعليم والاستعانة بالقوائم البريدية الاكترونية وصفحات الويكي، و التعلم عن بعد وغيرها (عبد الله التركماني ،

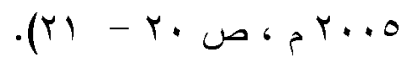

r) محو الأمية المعلوماتية وذلاك من خلال اعتصاد فلسفة تربوية تساعد على إكساب الطلاب

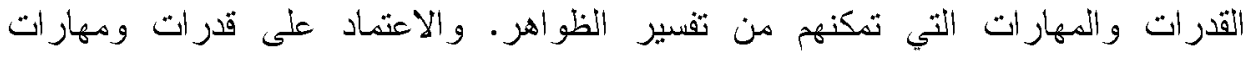

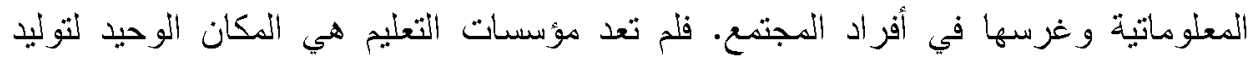

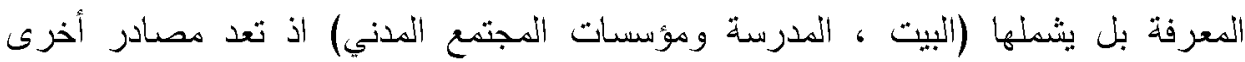

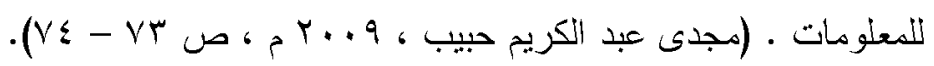

r) التمكين الإداري للمؤسسات التعليمية وذلك بإعطاء قدر من المرونة للمؤسسة التعليمية حتى

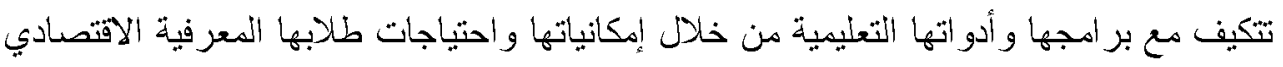

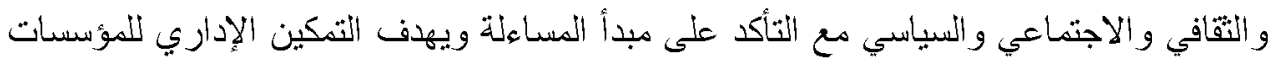

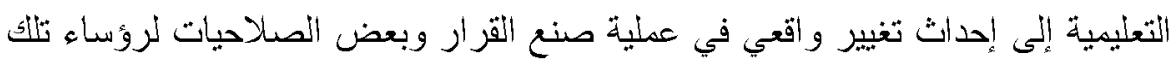

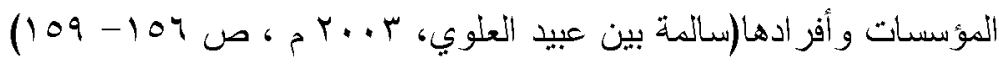




\section{محو الأمية المعلوماتية لدى طلاب الملدرسة الثانوية العامة في ضوء متطلبات مجتمع المعرفة}

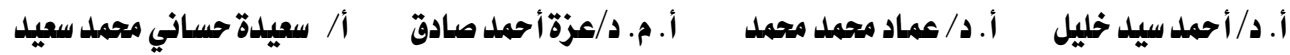

؛) التحول من استهلالك المعرفة إلى إنتاجها حيث بعتبر نجاح النظم التعليمية متوقف على قدرتها

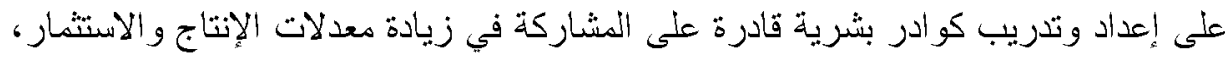

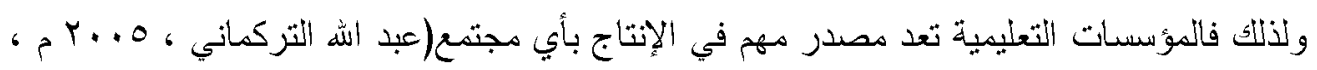
ص •

0) تحديث أنماط التعليم لبناء مجتمع المعرفة: في ظل مجتمع المعرفة لابد من الاهتمام بتوظيف

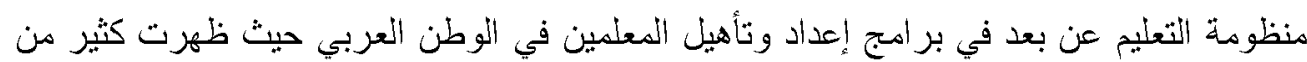

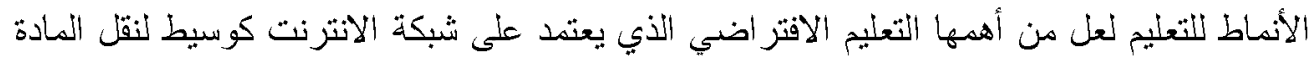

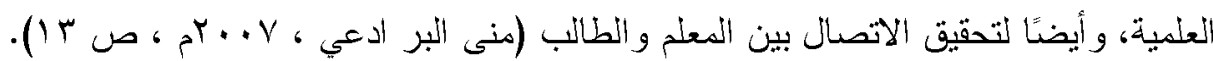

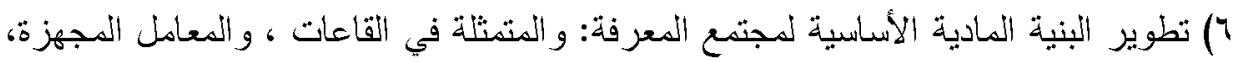

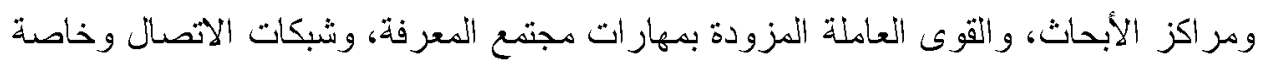

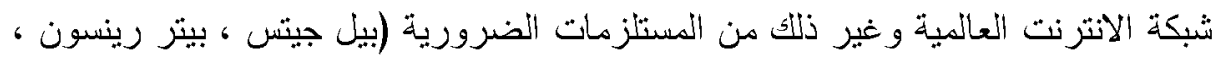

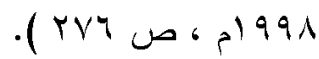
؛- انعكاسات مجتمع المعرفة على المدرسة الثانوية العامة في مصر

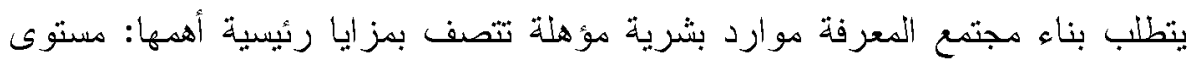

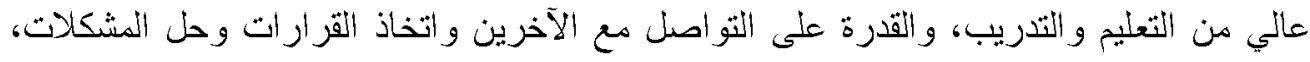

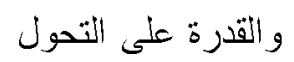

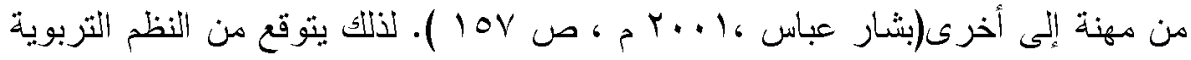

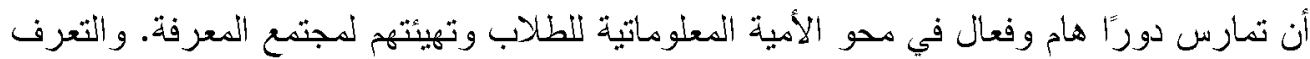

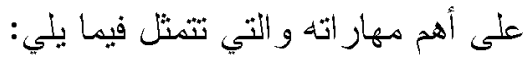

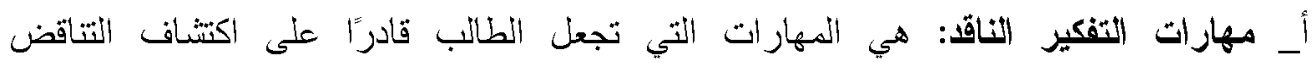
و المغالطات في النص وتحليله وتفسيره ومقارنته بغيره من النصوص لإصدار الحكم حول

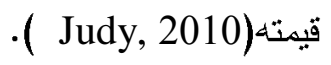
ب_ مهارات الاتصال الفعال: وتعني المهارات التي ينتج فيها الطلالب المعلومات وينقلها ويتبادلها

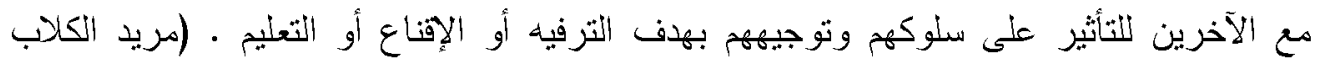
$($ r r.tro

جـ مهارات التعلم الذاتي: المهارات التي تركز على سعى الطالب بنفسه للأوصول للمعلومات

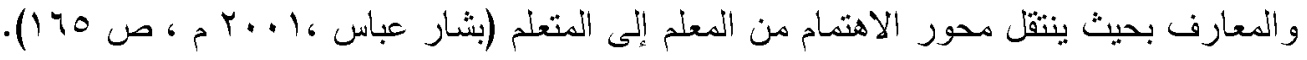




\section{محو الأمية المملوماتية لدى طلاب الملدرسة الثانوية العامة في ضوء متطلبات مجتمع المعرفة}

\section{أ. د/أحمد سيد خليل أ. د/ عماد محمد محمدلأ. م. د/عزة أحمد صادق أ/ سعيدة حساني محمد سعيد}

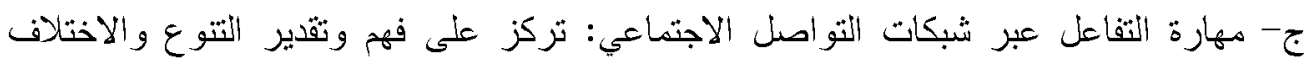
الثقافي على المستويات المحلية و العربية و العالمية، والمشاركة في مجتمعات افتر اضية، وتحليل

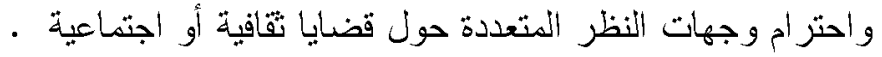

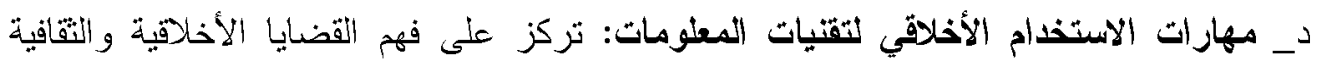

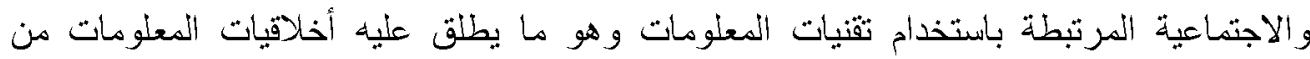

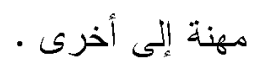

\section{رابعًا : طبيعة وخصائص طلاب المرحلة الثانوية العامـة وأهدافها}

يو اجه التعليم على مسنتوى العـالم حقبة تغيير ات سريعة وتكيف لم بحدث من فبل نتيجــة

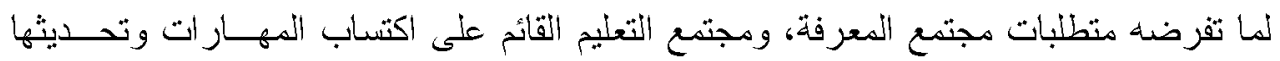

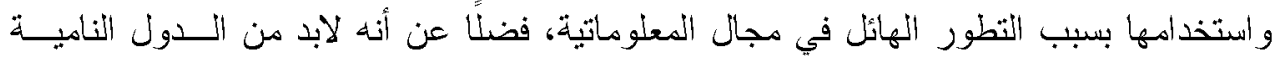

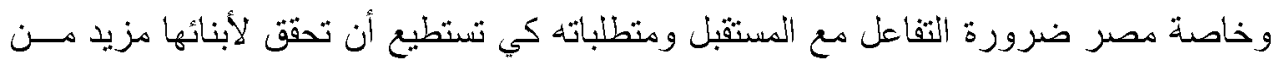
التقدم و الرفى. - وخده.

فالتعليم الثانوي العام له مكانة في السلم التعليمي ، ويعمل في إطار سياسة تعليمية عامة

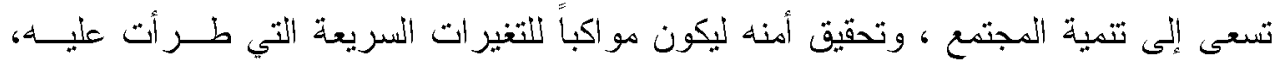

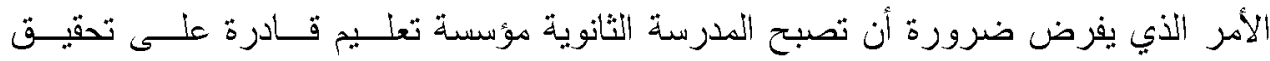

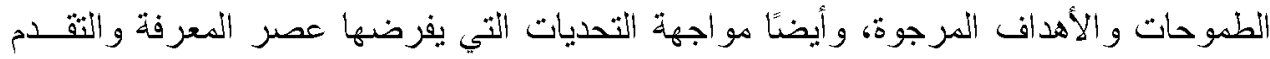

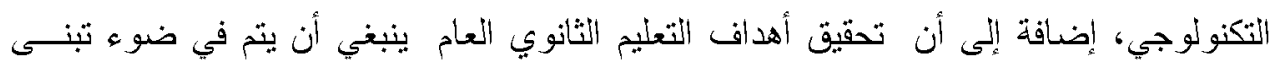

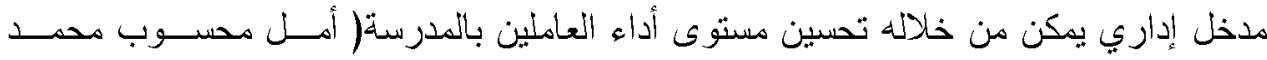

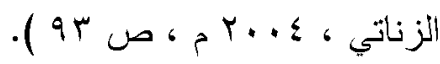

و المدارس الثنانوية العامة رغم ما فيها من إيجابيات وانجاز ات إلا أنها ما زالت لــديها

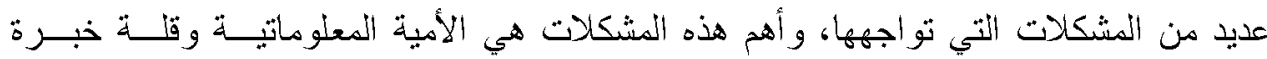

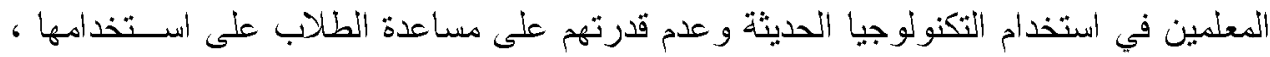

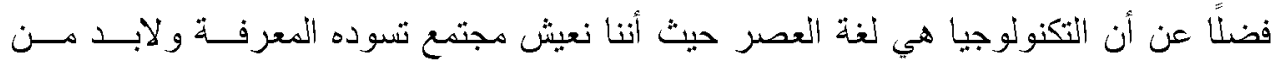

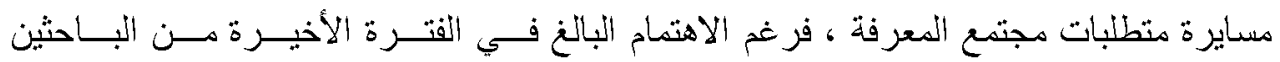

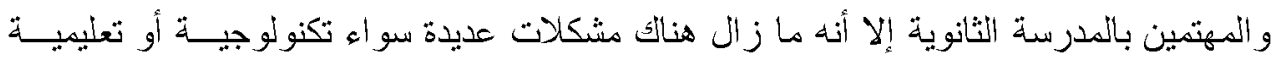

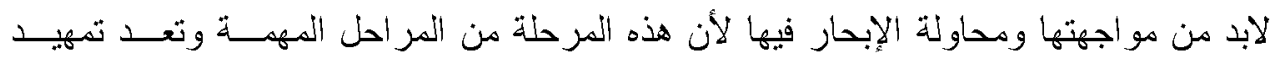

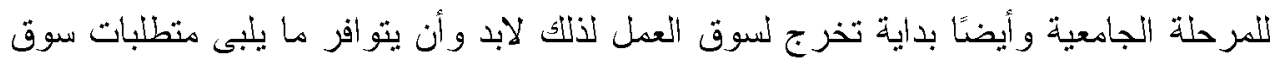
العمل و الذي يعتمد على المعرفة والمعلوماتية و التكنولوجيا. 


\section{محو الأمية المملوماتية لدى طلاب الملدرسة الثانوية العامة في ضوء متطلبات مجتمع المعرفة}

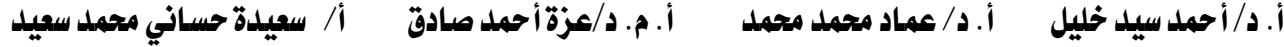

وتغطى المدارس بالتعليم الثانوب في مصر ثلاثئة أنواع هي : ثانوية عامة ، وثانويــة فنيــة ،

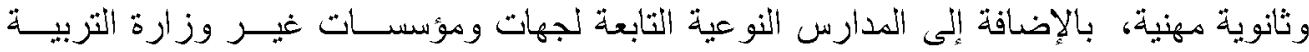

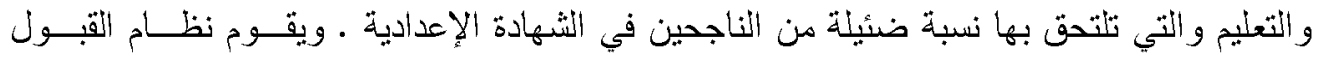

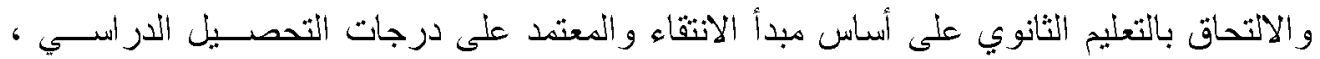

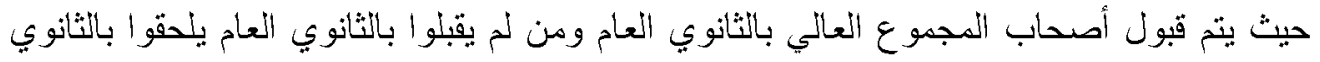

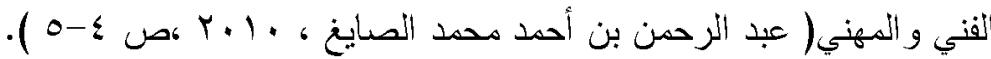

$$
\begin{aligned}
& \text { أ- خصائص طلاب المرحلة الثانوية }
\end{aligned}
$$

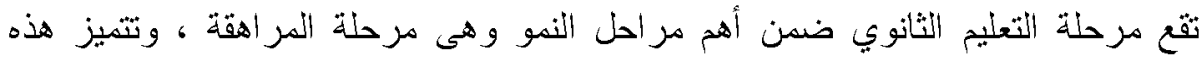
المرحلة بعدة خصائص منها العقلية والانفعالية و الاجتماعية و التي يجب أن تلقى اهتمامًا كبيرًا

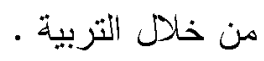

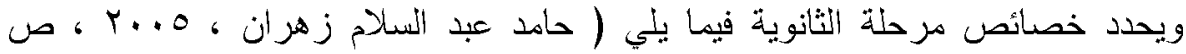

$$
\begin{aligned}
& :(\leqslant r \leqslant-r \lambda r \\
& \text { 1 ) النمو الجسمي : }
\end{aligned}
$$

حيث تزداد في هذه المرحلة مفهوم الذات الجسمية ، ويزداد الطول والوزن عند الجنسين، ويزداد الاهتمام بمظهر الجسم وصحته ، كما يظهر في مرحة الثانوية العديد من أثُكال العنف

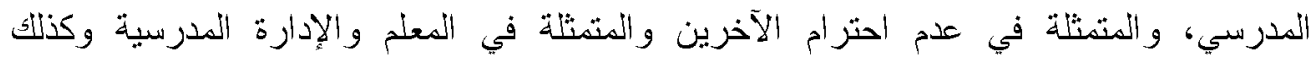
الأصدقاء ، الذى ينعكس بدوره على السلطة السياسية المتمثلة في السلطات المكونة للنظام السياسي ولئي ، ويمكن تسمية ذلك بالعنف السياسي ، مما يتطلب و عبا سياسيا وتربية سياسية لاى هؤلاء الطلاب

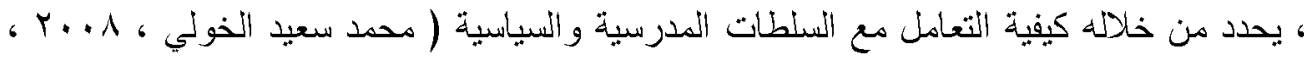

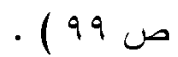

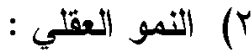

وتعد هذه الفترة بالمرحلة الثانوية فترة نمو عقلي ، وبالتالي يقع على عاتق المدرسة الاهتمام

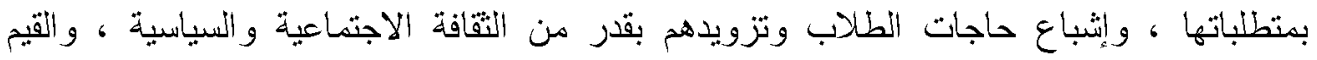
و المهار ات التي تنكهم في نهاية هذه المرحلة من ممارسة حقوقهم وو اجباتهم المختلفة ( محمد سيد

$$
\begin{aligned}
& \text {. } \\
& \text { r) النمو الانفعالي : }
\end{aligned}
$$

وبما أن شخصية المراهق في المرحة الثانوية تسعى إلى الاستقلال عن الأسرة والانفتاح

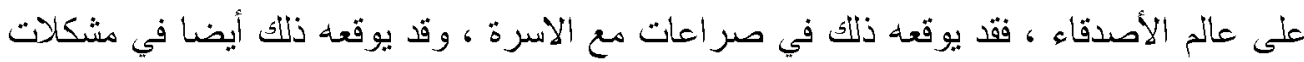




\section{محو الأمية المعلوماتية لدى طلاب الملدرسة الثانوية العامة في ضوء متطلبات مجتمع المعرفة}

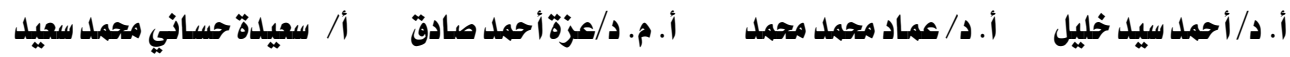

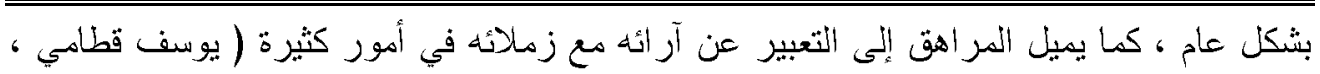

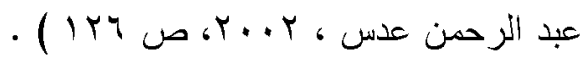

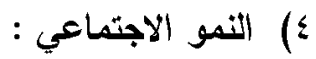

وتتضح هنا الز غبة في الميل إلى الجماعة ، ويظهر الثعور بالمسئولية الاجتماعية ، و الميل

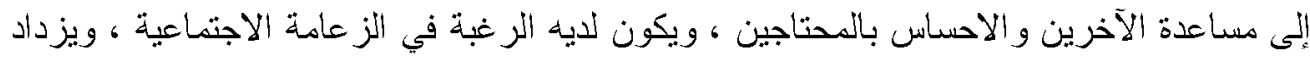

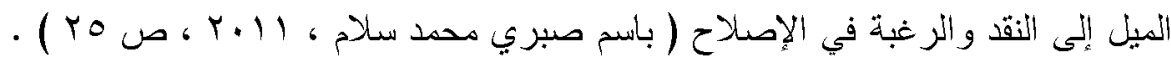
ب- أهداف المرحلة الثانوية العامة الثية

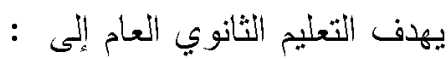

$$
\begin{aligned}
& \text { 1- الكثف عن ميول الطلاب وقدر اتهم واستعداداتهم • } \\
& \text { r- العناية بالمتفوقين و المعاقين من الطلاب . }
\end{aligned}
$$

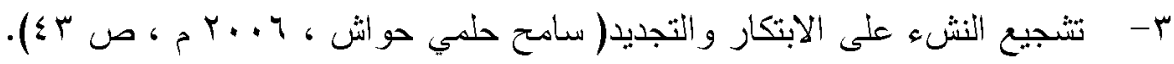

$$
\text { ع - نقل الخبر ات و المعارف و المهار ات و الاستفادة منها . }
$$

0- التركيز على التكنولوجيا الحديثة في نظام التعليم بشكل عام .

$$
\text { צ- البحث العلمي وتوفير المعلومات من خلال نتائج الأبحاث . }
$$

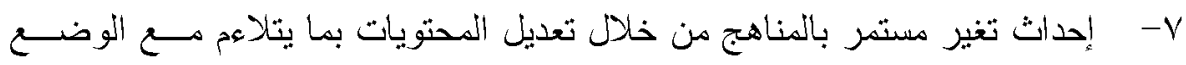

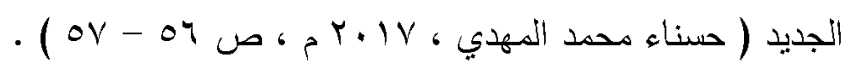

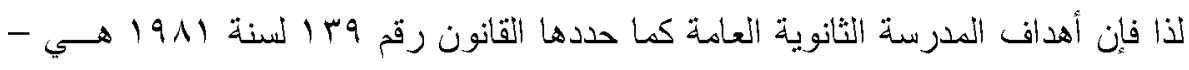

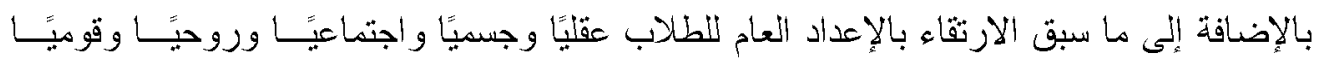

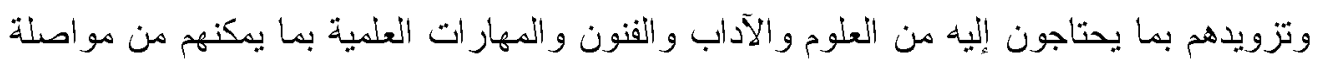

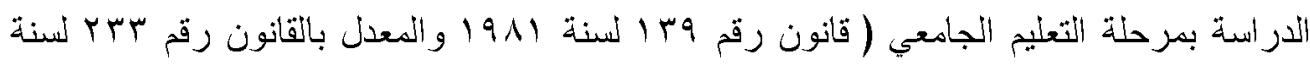




\section{محو الأمية المعلوماتية لدى طلاب الملدرسة الثانوية العامة في ضوء متطلبات مجتمع المعرفة}

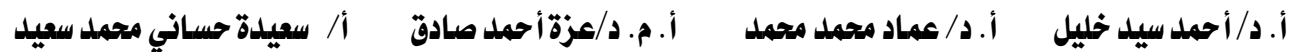

$$
\text { المراجع }
$$

1. أحمد أنور بدر( 1999م ) : علم المعلومات والمكتبات : دراسات في النظرية

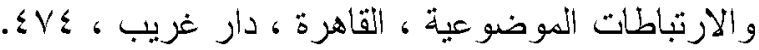

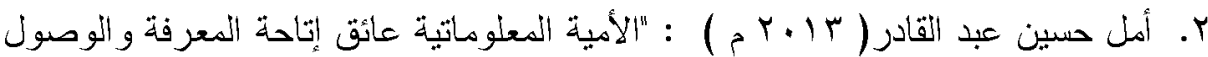

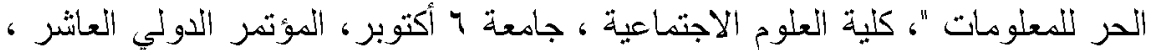
لقسم المكتبات و الوثائق و المعلومات ، كلية الآداب ، جامعة القاهرة .

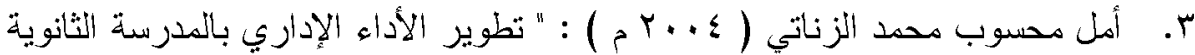

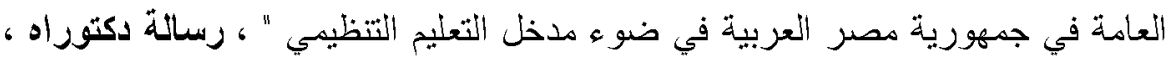
غير منشورة ، كلية التربية ، جامعة عين شمس. ؛. باسم صبري محمد سلام ( 11.ب م ) : فاعلية تطوير منهج التربية الوطنية لتنمية

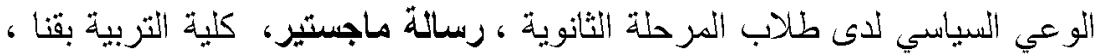

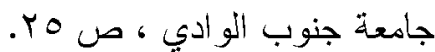

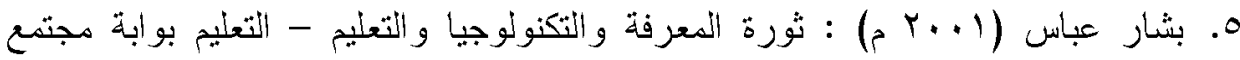

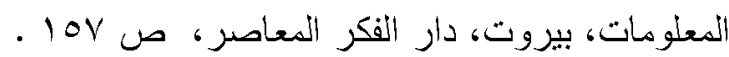
4. بيل جيتس ، بيتز رينسون ( 991 (م) : المعلوماتية طريق المستقبل، ترجمة عبد السلام

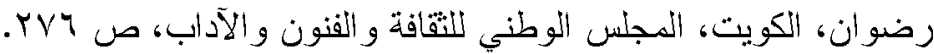

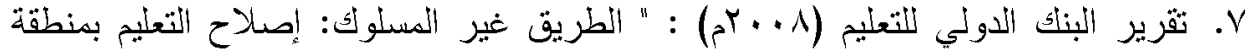

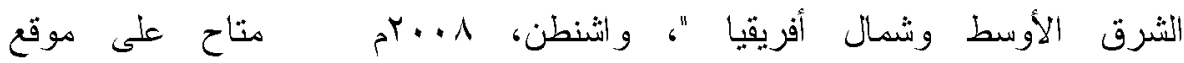

http//siteresources.worldbank.org/INTMENA/Resour-summary->. (ARB.pdf $>$ (10feb.2011 A. حاتم عبد الرحمن أبو السمح ، صداح محمد رحال (بسكا هـ) : العصر الزقمي

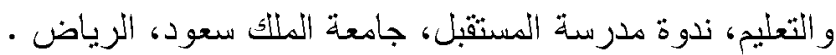

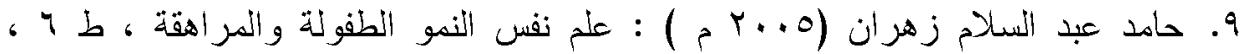

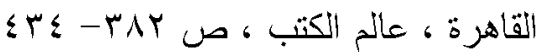

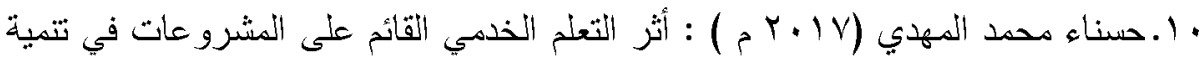
المهار ات البيئية الزر اعية وبعض عمليات العلم لدى طلاب التعليم الثانوي الفني الزراعي ، رسالة ماجستير ، كلية التربية ، جامعة جنوب الو ادي . 


\section{محو الأمية المعلوماتية لدى طلاب المدرسة الثانوية العامة في ضوء متطلبات مجتمع المعرفة}

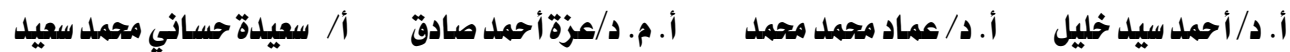

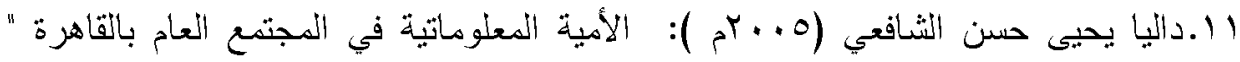

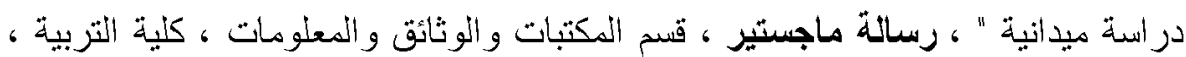

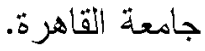

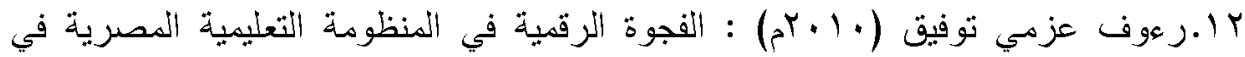

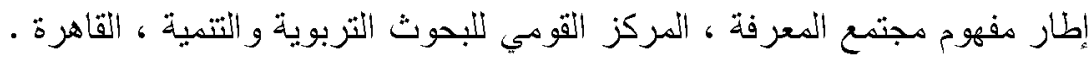

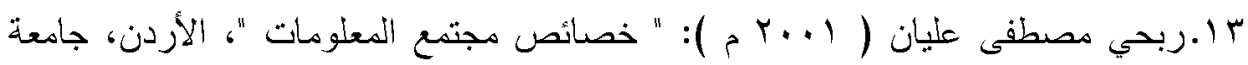
البلقاء التطبيقية.

؛ ا.ربحي مصطفى عليان( ب.. ب): دراسات في علوم الككتبات والتوثيق و المعلومات ،

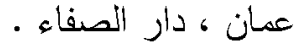

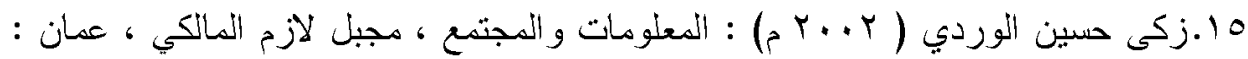

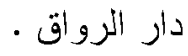

4 ا. سالمة بين عبيد العلوي( ب . . م م ) : " تحديات الاقتصاد المعرفي على النظام التربوبي في المملكة العربية السعودية"، رسالة ماجستير ، كلية التربية ، جامعة الملاك سعود .

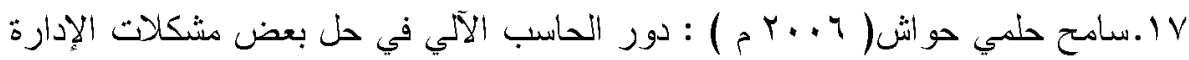

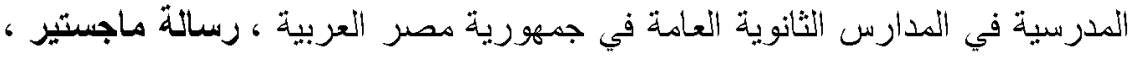
معهد الدر اسات و البحوث التربوية قسم أصول التربية جامعة القاهرة .

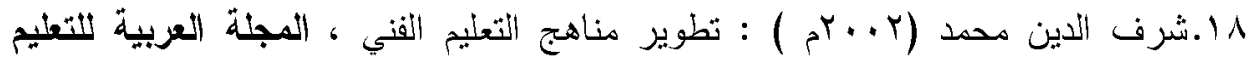
التقني ، الاتحاد العربي للتعليم التثني ، الأمانة العامة ، العراق ، مج 19 ، عاله

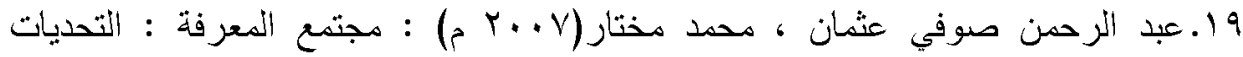

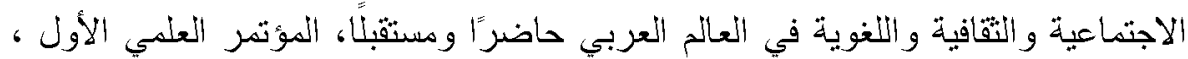
كلية الآداب و العلوم الاجتماعية ، منشورات جامعة السلطان قابوس ، مسقط ، سلطنة

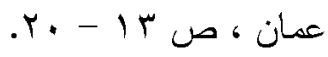

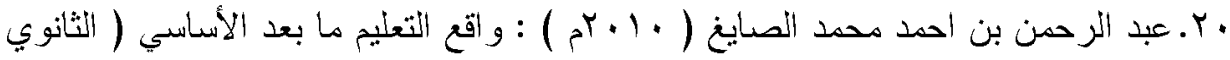

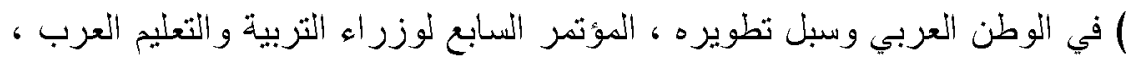
المنظمة العربية للتربية و التقافة و العلوم ، مسقط ، سلطنة عمان ، V-N مارس.

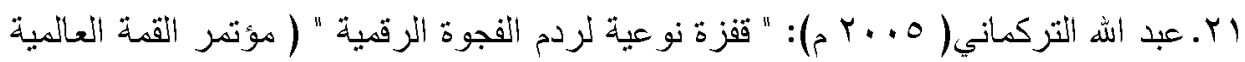

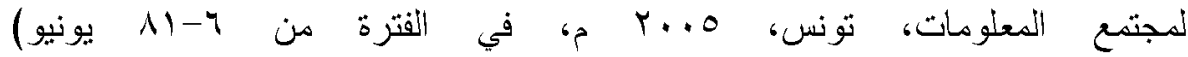
(>march2011)>http://alarabiclub.org/index.phpNov.2010IY 


\section{محو الأمية المعلوماتية لدى طلاب الملدرسة الثانوية العامة في ضوء متطلبات مجتمع المعرفة}

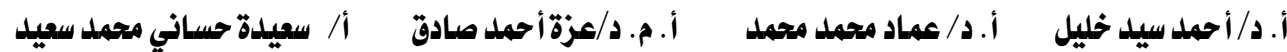

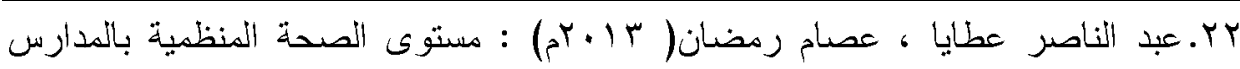
الثانوية من وجهة نظر معلمي التعليم الثنانوب العام بمصر ، مجلة النجاح للأبحاث العلوم بهم الإنسانية ، كلية التربية ، جامعة الأزهر هلهر ، القاهرة.

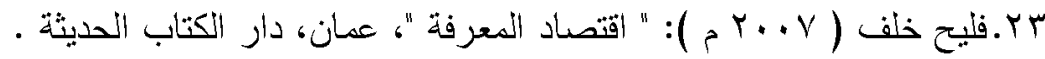

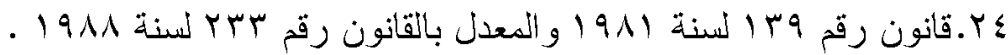

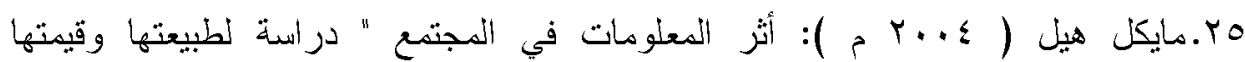
و استعمالاتها "، ترجمة: شادن اليافي ( مركز الإمار ات لللدر اسـات و البحوث) .

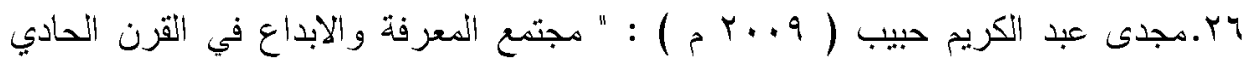

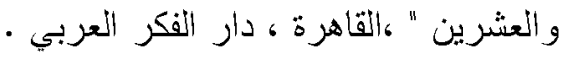

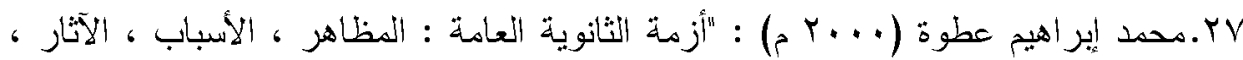
الحلول" ، مؤتمر جودة التعليم في المدرسة المصرية : التحديات والمعايير والفرص ،

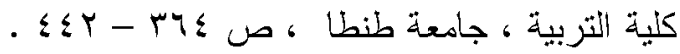

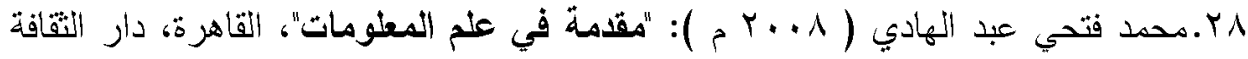
العلمية أمية

و Y. محمد مسعد أحمد عبد المقصود (IV) متطلبات مجتمع المعرفة دراسة حانة "، رسالة ماجستير، كلية الدراسات العليا للتربية، جامعة القاهزة .

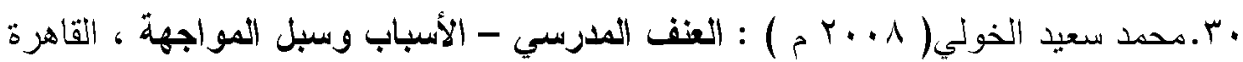

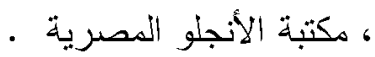

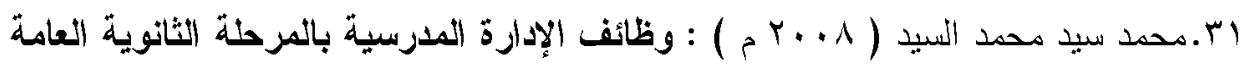

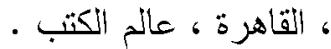

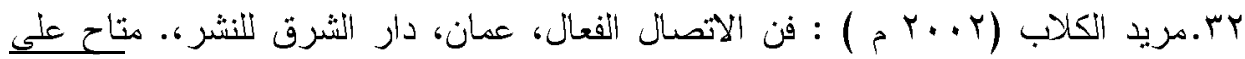

الموقع (3Feb.2001) بس. المكتب الإقليمي للاول العربية( r . . r م) : ثقرير التتمية الإنسانية العربية " نحو إقامة المعرفة " ، برنامج الأمم المتحدة الإنمائي والصندوق العربي للإنماء الإتصدادي والاجتماعي ، عمان - ولن

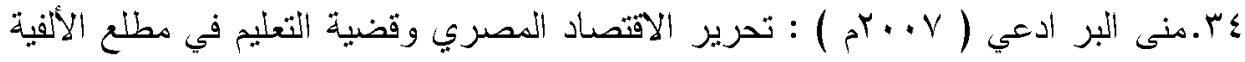

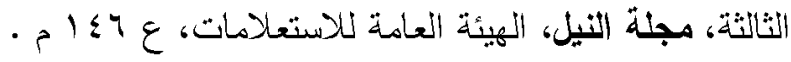




\section{محو الأمية المعلوماتية لدى طلاب الملدرسة الثانوية العامة في ضوء متطلبات مجتمع المعرفة}

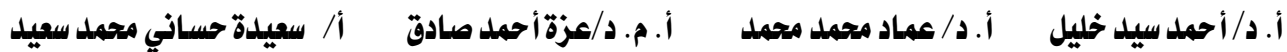

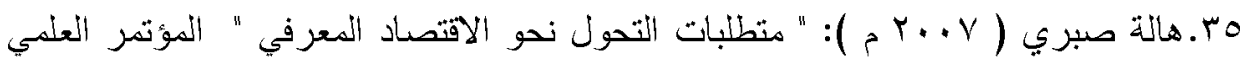

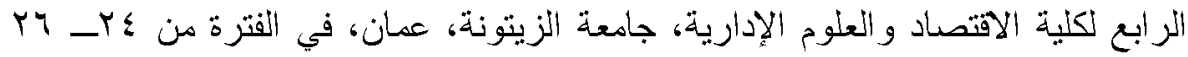

$$
\begin{aligned}
& \text { مارس: صن ع } \\
& \text { بس. هبة إبر اهيم جودة إير اهيم(Y ( • م م ) : " تطوير اعداد أخصدئي الاعلام التربوي بمصر } \\
& \text { في ضوء متطلبات مجتمع المعرفة "، معهد الدراسات التربوية ، جامعة القاهرة . }
\end{aligned}
$$

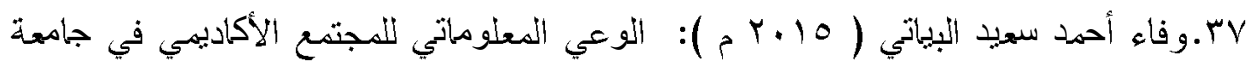

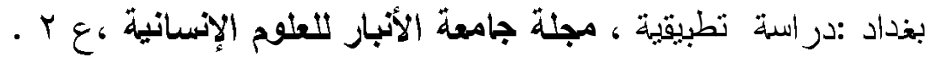

$$
\begin{aligned}
& \text { هب. يوسف قطامي ، عبد الرحمن عدس (Y . . r م ) : علم النفس العام ، القاهرة ، دار الفكر } \\
& \text { - العزبي } \\
& \text { المراجي الأجنبية : المربية }
\end{aligned}
$$

39 -American Library Association (1989): Presidential Committee on Information Literacy: Final Repot. Washington, D.C. Available at:http://www.ala.org/aia/mgrps/divs/acrl/publications/whitepapers/presidenti al.cfm

40 -Eisenberg, B.M "Information Literacy: Essential Skills for the Information Age". Journal of Library \&Info)41 -Doyle, C.S. (1992): Outcome measures for information literacy within the national education goals of 1990: final repot of the National Forum on Information Literacy. Summary of findings. Washington, DC:US rmation Technology.2008.28(2):39-47.

42 -Department of Education. (ERIC document no, ED 351033). Available at:

http://web.archive.org/web/20061219041704/http://eric.ed.gov/ERICDocs/da ta/ericdocs2/content-storage-01/0000000b/80/23/4a/12.pdf

43 -Fisher, Saul. Open Technologies and Resources for the Humanities- and Cooperative Consequences. Arts and Humanities in Higher Education.2006. vol 5, no.2. Pp.127-145

44 -Judy lee:" Teaching critical thinking: Based Environment in Higher Education", University of Alberta Edmonton, Alberta. Canada, vol49, no4,2005, p.29.nov.2009<http://eric.ed.gov/ERIc Web portal /search/detailmini. jsp.> (2March 2010)

45 -Lannuzzi, Patricia. Information Literacy Goals and Objectives. -Florida State: Florida International Libraries, Florida International Universities (FIU), 1999. 